\title{
Reliability-based calibration of partial factors for the design of temporary scaffold structures
}

\author{
Eline Vereecken*, Wouter Botte, Didier Droogné, Robby Caspeele \\ Department of Structural Engineering, Ghent University, Ghent, Belgium \\ *Corresponding author at Technologiepark-Zwijnaarde 60, 9052 Ghent, Belgium; \\ eivereec.vereecken@ugent.be
}

\begin{abstract}
In this work, partial factors for the design of temporary scaffold structures are calibrated based on reliability calculations. Scaffolds are commonly designed in accordance to rules in standards (e.g. EN12811, EN12810) and information found in codes of good practice. However, there is no clear proof that these design procedures result in an appropriate and consistent safety level for scaffold structures. The present study proposes appropriate target reliability levels for façade scaffolds, based on which partial factors are determined. The results are based on simulations of different scaffold design situations, considering samples generated by LHS. The results of these simulations are processed by applying FORM analyses for buckling and yielding of the scaffold elements. As such, the inherent reliability corresponding to current design practice is determined. Based on the inherent and target reliabilities, partial factors are calibrated using two methods: the Adjusted Partial Factor Method and an optimisation procedure based on least-square averaging. Concluding, annual reliability indexes in the range 2.5-3.5 are found. These lead to partial factors lower than or equal to those used in current design practice. Hence, there is an optimisation possible in the design of temporary structures compared to current practice, leading to more economical scaffold designs.
\end{abstract}

Keywords: Safety factors, Calibration, Temporary structures, Reliability \& Risk Analysis, Structural reliability, Optimization

\section{Introduction}

Structures are commonly designed on the basis of a semi-probabilistic design format, i.e. using a partial factor approach or a Load and Resistance Factor Design (LRFD) format. These safety factors are used to increase loads and reduce resistance in order to reach an imposed level of safety. The factors to be used are calibrated in relation to a target safety level on the basis of structural reliability calculations through an optimisation process (Gayton, Mohamed, Sorensen, Pendola, \& Lemaire, 2004) or on the basis of a simplified approach (König \& Hosser, 1982). According to (Baravalle \& Köhler, 2019), calibration of design codes could be considered as a decision problem under risk. In this decision problem, society is the rational decision maker and the reliability requirements (target reliability levels) with the corresponding code reliability elements (safety factors) are the decision variables. When the design is executed according to the reliability elements (partial factors, load combination factors and modification factors) imposed by the code maker, neither the failure probability, nor the failure consequences are directly considered in the design. However, the reliability elements are calibrated to a target 
safety level, which is then inherent to design according to the code reliability elements. The domain of applicability of the reliability elements is limited to standardised failure consequences, failure modes and uncertainties. In general, the risk-based calibration of the reliability elements is subdivided into two tasks: the calibration of the optimal reliability level and the reliability-based calibration of the reliability elements for the obtained target reliability level.

The first task concerns the derivation of optimal reliability levels. In (Fischer, Viljoen, Köhler, \& Faber, 2019) it is clearly explained how optimal and acceptable reliabilities for structural design can be derived. The latter should be based on a monetary optimisation and societal risk acceptance. In (Fischer et al., 2019), the monetary optimisation as developed by (Rackwitz, 2000) is reviewed and extended to incorporate societal risk acceptance with respect to life safety. With respect to the calibration procedure for determining the reliability elements (safety factors), commonly an optimisation process is used where the control variables are the reliability elements (e.g. partial factors) in order to reach as close as possible the code objective (defined by the target reliability). An example procedure for code calibration is given by (Gayton, et al., 2004). In this procedure first the class of structures for which the code is aimed, mechanical and probabilistic models and a target reliability should be defined. Specific design situations within the structure class and their relative frequency of occurrence are considered. These are evaluated and implemented in a penalty function punishing the deviation of the design based on the code from the objective. This input is required in the optimisation of the reliability elements (e.g. partial factors), where the most appropriate code format is determined, i.e. the one closest to the objective. Sørensen, Kroon, and Faber (1994) apply this procedure for code calibration with as penalty function a least-squares optimisation. The target reliability index considered here is estimated, based on statistical decision theory, human safety considerations (acceptable risk for a single person and for society) and an estimated mathematical economic optimum. The target failure probability for economic considerations is determined from a minimisation of the failure costs.

In (Toft \& Sørensen, 2011) partial safety factors for the design of wind turbines are calibrated according to a predetermined reliability level (based on a cost-benefit analysis ) and a probabilistic model. Partial safety factors to be used in traditional deterministic design of wind turbine blades are estimated using stochastic models and limit state equations. These stochastic models are altered and the partial factors required to achieve a certain target reliability level are derived when using the altered stochastic models. The partial safety factors are hence calibrated in a reference case and for different variations of the physical, model and statistical uncertainties An alternative way for calibrating partial factors is described in (Abd Alghaffar \& DymiotisWellington, 2007). Here, a partial factor is defined as the ratio of the characteristic value of a design parameter to the assumed design value. The partial factor will hence depend on the uncertainty in the design parameter under consideration (represented by the coefficient of variation), the target reliability, the sensitivity factor of the design parameter considered and the percentile used for the calculation of the characteristic value. Other examples of code calibration can be found in (Fiorillo \& Ghosn, 2018) and (Zou \& Ping Hong, 2011). In (Fiorillo \& Ghosn, 2018), the importance load modifier used in LRFD safety check equations is calibrated. This importance factor can then be provided to practicing engineers in tabular format. In (Zou \& Ping Hong, 2011) the concrete resistance factor for FRP-confined reinforced columns is calibrated. Previous examples show that calibration is used in almost all codes and standards and is often necessary when new techniques or materials become available or when for an existing technique these easy to use reliability elements to achieve a safe design are still lacking or not properly defined.

Up to date, reliability based design of temporary structures has received only limited attention. André, Beale, and Baptista (2017) developed a risk-informed structural design 
methodology for bridge falsework systems. However, here the design is not based on partial factors, but on robustness and fragility indices. These indices could be used to reduce the risk associated to plan, design, assembly and operation of bridge falsework systems. Tanner, Hingorani, and Soriano (2018) performed fundamental research on the required safety level of temporary structures and proposed an approach for the derivation of target safety levels for temporary structures. In this article, a consistent methodology is developed for the reliabilitybased design of temporary structures, focusing on the derivation of reliability elements for façade scaffolds. In particular, the reliability-based framework and target reliability levels are applied to calibrate partial factors as used in the Eurocode framework. The target reliabilities in the current Eurocodes can be considered as economical optimal values for normal long-term structures. They are calculated based on a minimisation of the expected value of the total lifetime cost. It is however questioned whether the same level of safety needs to be applied to temporary structures, such as façade scaffolds and it is investigated whether human safety considerations dominate the decision making with respect to target reliability levels for temporary structures.

Reliability-based design codes for scaffolds are scarce. The ASCE standard on 'Design Loads on Structures During Construction' (ASCE 2002) addresses temporary structures used during construction (i.e. not only façade scaffolds), where the design loads according to this standard provide a level of safety of temporary structures used in construction. This safety level is comparable to the level of safety of completed structures. Furthermore, factors of safety for the design of scaffolds in the United States can be found in 'Temporary Structure Design' (Souder 2014), also providing scaffolding factors of safety. In Australia and New Zealand, the standard AS/NZS 1576.1:2010 'Scaffolding General requirements' (Standards Australia/Standards New Zealand, 2010) provides load combinations to be used in the design of scaffolds. However, it is not clear on which reliability level these load factors are based. In Europe currently, the design of scaffolds follows the standards EN 12810, EN 12811 and several other 'codes of good practice' (such as the German DIN 4420, the 'Richtlijn steigers' for the Netherlands (VSB Vereniging van Steiger Hoogwerk en Betonbekistingbedrijven Bouwend Nederland, 2017)), the 'Code of Practice for Access and Working Scaffolds' from the Irish Health and Safety Authority (2005) etc.). However, it is unclear whether these design guidelines follow a reliability-based approach, similar to the one prescribed in EN 1990. In the following, target reliability levels are derived considering both human safety requirements and an economic optimisation. Next, a methodology for performing probabilistic calculations on façade scaffolds is elaborated. Using this probabilistic framework for the calculation of different scaffold designs and taking into account the suggested target reliability levels, consequently two alternative approaches are used for the derivation of appropriate partial factors, i.e. the Adjusted Partial Factor Method (APFM) and an optimisation procedure based on least-square averaging. The partial factors finally suggested for further applications, take into account common practical constraints for partial factors as applied in the Eurocode framework.

\section{$2 \quad$ State of the art}

\subsection{Current design procedure of scaffolds}

In Europe, scaffolds are currently designed according to EN 12811-1, considering different classes depending on the loads applied on the scaffold. EN 12811-1 considers six classes, where a higher class represents higher loads. Some basic terminology of these scaffolds is introduced in Figure 1. It must be pointed out that the elements used in scaffold construction have standardised dimensions. The transoms and ledgers can only have a limited number of practical 
lengths: $0.73 \mathrm{~m}, 1.09 \mathrm{~m}, 1.4 \mathrm{~m}, 1.57 \mathrm{~m}, 2.07 \mathrm{~m}, 2.57 \mathrm{~m}$ and $3.07 \mathrm{~m}$; the standards on the other hand, are usually $2 \mathrm{~m}$ high (Layher, 2017; Scafom International b.v., 2010).

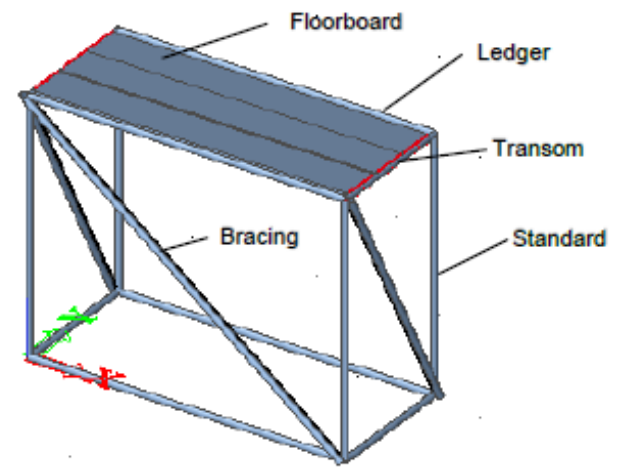

Figure 1. Terminology of scaffold elements

According to EN 12811-1, the load combinations that need to be considered in the design of façade scaffolds are the service condition and the out-of-service condition.

The service condition contains the following loads:

- Self-weight;

- Uniformly distributed service load depending on the class of the scaffold, acting on the working area or on the most unfavourable decked level (usually the top storey);

- $50 \%$ of the previous load on the working area at the next level above or below;

- Working wind load (uniformly distributed velocity pressure of $0.2 \mathrm{kN} / \mathrm{m}^{2}$ ) or horizontal load allowance due to operations in use.

For the out-of-service condition, the loads that need to be considered are:

- Self-weight;

- A fraction of the uniformly distributed load depending on the load class ( $0 \%$ for class 1, 25\% for class 2 and 3 and $50 \%$ for class 4,5 and 6 );

- Maximum wind load.

The partial factors on actions prescribed in EN 12811-1 are 1.5 for permanent and variable loads and 1 for accidental loads. For resistance properties, a factor $\gamma_{M}=1.1$ is used for steel or aluminium components (more ductile materials), 1.25 for brittle metallic materials and 1.3 for timber. Hence, the most important differences with the design of structural steel in Europe, are the use of a partial factor of 1.5 for the permanent loads (instead of 1.35 as prescribed in EN1990) and a factor of 1.1 for the steel properties. It must be pointed out that the partial factor $\gamma_{M}$ derived in this work will correspond to $\gamma_{M 0}$ and $\gamma_{M 1}$ in structural steel design in Europe, which are both equal to 1 in EN 1993.

\subsection{Target reliabilities in current codes and standards}

In EN 1990, reliability indices are given for two reference periods, i.e. one year and 50 years. These are not explicitly linked to the design working life and generally differ from it. Also, no specific indicative values are available for temporary structures. The reliability indices according to EN 1990 are given in Table 1 for the ultimate limit state (ULS) for long-term structures. Practical application of these values will depend on the reference period considered in the verification, linked to the available probabilistic data of the time varying basic variables (Holický, Marková, \& Sýkora, 2014). As no transparent link is provided between the design working life and the target reliability, it is not clear which target reliability index needs to be used for a given design working life different from 50 years (Holický, 2016). 
Table 1: Reliability classification according to EN 1990 and recommended minimum values for $\beta$ (ULS) (CEN, 2002)

\begin{tabular}{l|l|l}
\hline \multirow{2}{*}{ Reliability classes } & \multicolumn{2}{|l}{ Reliability index $\boldsymbol{\beta}$} \\
\cline { 2 - 3 } & $\beta_{a}$ for $T_{a}=1$ year & $\beta_{d}$ for $T_{d}=50$ years \\
\hline 3 - High & 5.2 & 4.3 \\
2 - Normal & 4.7 & 3.8 \\
- Low & 4.2 & 3.3 \\
\hline
\end{tabular}

In ISO 2394:2015 (ISO, 2015), the reliability levels are derived for a one year reference period, with a distinction made between economic considerations and human safety. For human safety, the tentative target reliabilities are given in Table 2 . Here, $K_{t}$ is a parameter proportional to the marginal costs associated with the considered safety measures, and inversely proportional to the expected number of fatalities and the social willingness to pay for a unitary change in mortality.

Table 2. Tentative minimum target reliabilities related to one year reference period and ULS, based on the Life Quality Index (LQI) acceptance criterion (ISO, 2015)

\begin{tabular}{lll} 
Relative life saving costs & Range for $K_{t}$ constant* & LQI target reliability \\
\hline Large & $10^{-3}-10^{-2}$ & $\beta=3.1\left(P_{f} \approx 10^{-3}\right)$ \\
Medium & $10^{-4}-10^{-3}$ & $\beta=3.7\left(P_{f} \approx 10^{-4}\right)$ \\
Small & $10^{-5}-10^{-4}$ & $\beta=4.2\left(P_{f} \approx 10^{-5}\right)$ \\
\hline
\end{tabular}

${ }^{*} K_{t}$ is a constant equal to the ratio of the rise of the yearly safety cost with a unit increase in the global safety factor to the unit consequences of structural failure

The target reliability levels for economic considerations given in ISO 2394:2015 are based on the Probabilistic Model Code (PMC) of JCSS, which is based on a study performed by Rackwitz (2000). These reliability indices are given in Table 3.

Table 3. Tentative target reliability indices related to one year reference period and ULS (JCSS, 2001)

\begin{tabular}{|c|c|c|c|}
\hline $\begin{array}{l}\text { Relative costs of } \\
\text { safety measures }\end{array}$ & $\begin{array}{l}\text { Minor consequences } \\
\text { of failure }\end{array}$ & $\begin{array}{l}\text { Moderate } \\
\text { consequences of failure }\end{array}$ & $\begin{array}{l}\text { Large consequences } \\
\text { of failure }\end{array}$ \\
\hline Large & $\beta=3.1$ & $\beta=3.3$ & $\beta=3.7$ \\
\hline Normal & $\beta=3.7$ & $\beta=4.2$ & $\beta=4.4$ \\
\hline Small & $\beta=4.2$ & $\beta=4.4$ & $\beta=4.7$ \\
\hline
\end{tabular}

It may be pointed out that when applying ISO 2394:2015, for scaffolds, $K_{t}$ will be high, because the expected number of fatalities will be low. Hence, a low Life Quality Index (LQI) target reliability will be achieved. In view of economic considerations, façade scaffolds will have minor consequences of failure, also leading to a low value for the target reliability.

\section{$3 \quad$ Target reliability indices for temporary structures}

In section 4, a framework is developed to derive the reliability index corresponding to a certain scaffold design. This method was also adopted to derive the reliability inherent to the current design procedure. However, it is not clear whether this inherent reliability level is an appropriate target to aim at, considering human safety and economic optimisation of a scaffold. The target reliability levels mentioned in the previous section are all derived for long-term structures. However, scaffolds are temporary structures with a shorter lifetime and different economic and 
human failure consequences. Furthermore, due to the temporary character of the scaffolds, society may accept larger risks (i.e. accepting higher risks for temporary situations). Hence, in this part, target reliability indices will be derived for scaffolds, both for human safety requirements and economic considerations. These target reliabilities will be derived for a reference period of one year, since target reliabilities for one year are a more logical choice than for a reference period of 50 years, considering the short usage and temporary character of these scaffolds. Furthermore, also in the new ISO standard ISO 2394:2015, reference periods of 1 year are used to describe the target reliability.

\subsection{Target reliability considering human safety}

In literature, target reliability levels for human safety are proposed by e.g. Caspeele, Steenbergen, and Taerwe (2012). Using a reference period of one year, these target reliabilities can be based on the target probability of failure for individual risk, assuming a reference period of one year: $P_{f t, I R} \leq 10^{-5} / P_{c \mid f}$. Here, $P_{f t, I R}$ is the target failure probability for individual risk and $P_{c \mid f}$ the probability of casualty given failure. According to Steenbergen and Vrouwenvelder (2010) a value of 0.001 can be adopted for $P_{c \mid f}$, resulting in a target reliability index $\beta_{t}$ of 2.3 . Nevertheless, this value for $P_{c \mid f}$ might be slightly too conservative, as it should be lower than the probability of having at least one casualty. The probability of casualty for an individual person, given structural failure, can be lower than the probability of at least one casualty, when the residence time of an individual in, under or on a structure is small. Eldukair and Ayyub (1991) suggested the probability of at least one casualty in case of failure to be 0.005 , which results in a target reliability index of $\beta_{t}=2.88$. Finally, in fib Bulletin 80 (Caspeele, Steenbergen, $\&$ Sykora, 2016) $P_{c \mid f}=0.01$ was assumed, resulting in $\beta_{t}=3.1$.

\subsection{Target reliability considering economic optimisation}

To derive a target reliability based on an economic optimisation, Rackwitz (2000) proposed an objective function $Z(x)=B(x)-C(x)-D(x)$, where $B$ is the benefit resulting from the structure, $C$ the initial cost of construction and $D$ the cost due to failure. Searching an optimal value of the decision parameter $x$ which maximises the objective function $Z$, the optimal reliability level is obtained. According to (Van Coile, 2015; Van Coile, Caspeele, \& Taerwe, 2014), the objective function can be rewritten in the shape of equation (1).

$$
Z(x) \sim C_{0}(1+\varepsilon(x))\left[1+\xi \frac{P_{f}(x) \lambda}{\gamma}\right]
$$

Here, $\gamma$ is the continuous discount rate, $\varepsilon(x)$ represents the ratio of the additional costs when changing the design parameter $x\left(C_{1}(x)\right)$ to the basic costs $\left(C_{0}\right)$ and $\xi$ is the ratio of the failure cost to the initial construction cost. The parameter $\lambda$ represents the renewal rate when the time between renewals is modelled by an exponential distribution and $P_{f}(x)$ is the probability of failure at every renewal. It must be pointed out that in expression (1) the benefit resulting from the structure is left out, as this is assumed to be constant and will not influence the optimisation procedure. Hence, formula (1) needs to be minimised to maximise the objective function $Z$.

For the different parameters in expression (1), appropriate values should be used. The renewal rate $\lambda$ can be set equal to 1 as a reference period of 1 year is used, which is assumed to be equal to the average time between renewals. The discount rate $\gamma$ adopted for temporary structures should not be too small, as it makes no sense to balance most of the cost to be carried by future generations because of the small lifetime of scaffolds. On the other hand, the higher the discount rate, the lower the initial investment required to achieve the target reliability level. Hence, a lower discount rate is more appropriate for temporary structures. A discount rate in the range of $2 \%$ to $3 \%$ was adopted by Adeli and Sarma (2006). Also Holický (2012) indicated a discount rate of 0.03 in the average long run in Europe. Finally, the ratio $\xi$ for scaffolds is assumed to be less than 2, since the latter is the value applied for private houses. 
In the following, the influence of these different parameters on the optimum reliability is investigated. The chosen design parameter is the length of the ledgers, since it influences the load carried by each transom and thus impacts the main failure mechanism i.e. yielding of the transoms under service load. As an example, a scaffold of $2 \mathrm{~m}$ high and $30 \mathrm{~m}$ wide is considered. The ledger length $L$ is gradually increased. The stresses in the transoms for the different assumed ledger lengths are calculated analytically and a FORM analysis is performed to determine the reliability index $\beta$ for the limit state of yielding for different ledger lengths. The cost $C_{1}$ is calculated as $C_{1}=(n L+2(n+1)) /(n L)$. Here $n$ is an integer representing the number of ledgers of length $L$ that must be used to achieve a total length of about $30 \mathrm{~m}$. The factor 2 represents the height of the standards $(2 \mathrm{~m})$ and $n+1$ is the number of standards. As such, the first term in the sum represents the cost of the ledgers, whereas the second term represents the cost of the standards. The sum of these two contributions is divided by the length of the scaffold, to normalise the cost.

The influence of the discount rate on the objective function is represented in Figure 2. The minima of the objective function are situated around the same values for $\beta$ and varying the discount rate only has an effect for low reliability levels. Furthermore, the influence of the ratio $\xi$ of the failure cost to the initial cost is investigated. Since the real value of $\xi$ is difficult to determine, the following values are considered:

- $\xi=0.1$, assuming that only a few elements of the scaffold are damaged after lots of reuse; very limited economic consequences;

- $\xi=0.5$, when not all elements are damaged and some can be reused;

- $\xi=1$, when the only cost arising from failure is the total reconstruction of the scaffold;

- $\xi=2$, the value recommended for private houses.

The influence of varying $\xi$ is visualised in Figure 3 as a function of the reliability index. The objective function $Z$ has again a flat behaviour around its minimum and towards higher values of $\beta$. When increasing the initial cost $C_{0}$, the objective function with respect to the reliability index just shifts to higher values, as visible on Figure 4. Finally, the reliability levels corresponding to the minimum of the objective function can also be determined considering different scaffold classes. The absolute minimum of $Z$ for the different scaffold classes is situated at different values of the reliability index. However, the objective function plotted as a function of the reliability index again shows a quite constant behaviour (Figure 5). 


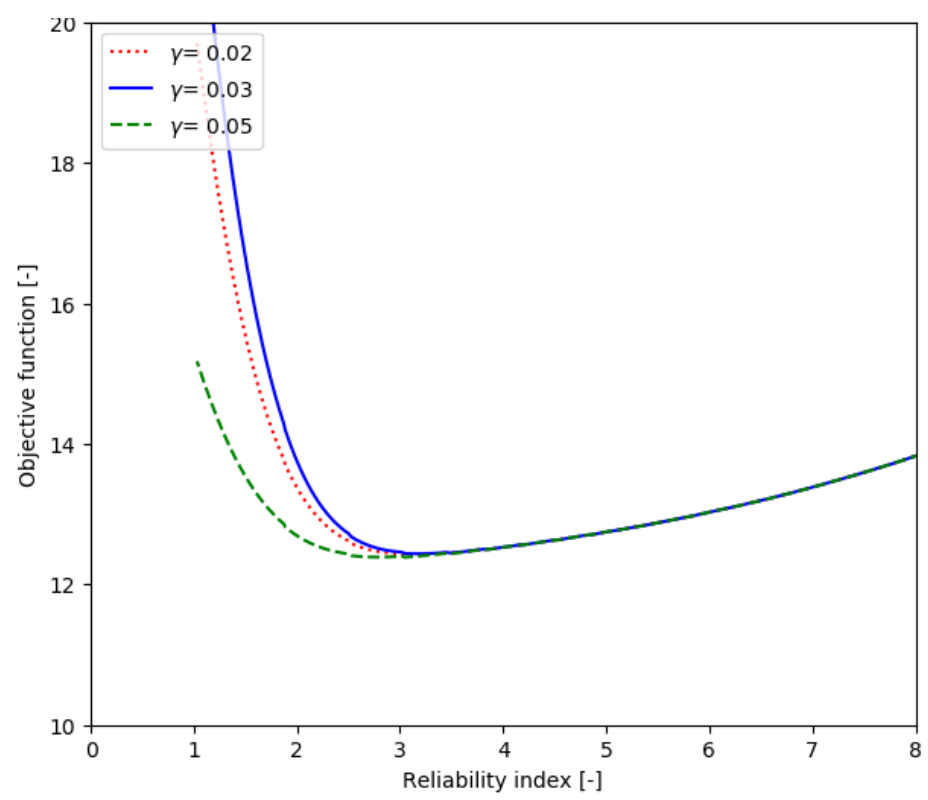

Figure 2. Objective function $Z$ in function of $\beta$ for different values of the discount rate $\gamma$ (scaffold of class 3 , transoms of $0.73 \mathrm{~m}, \xi=1$ and $C_{0}=1$ )

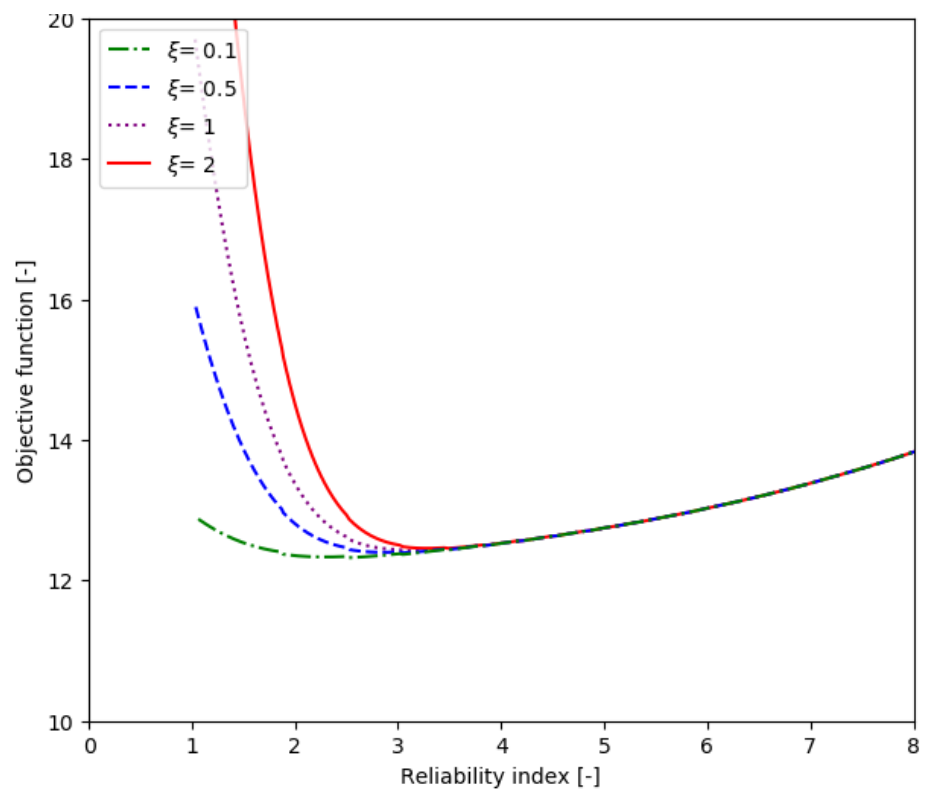

Figure 3. Objective function $Z$ in function of $\beta$ for different values of the ratio of the failure cost to the initial cost $\xi$ (scaffold of class 3 , transoms of $0.73 \mathrm{~m}, \gamma=0.02$ and $C_{0}=1$ ) 


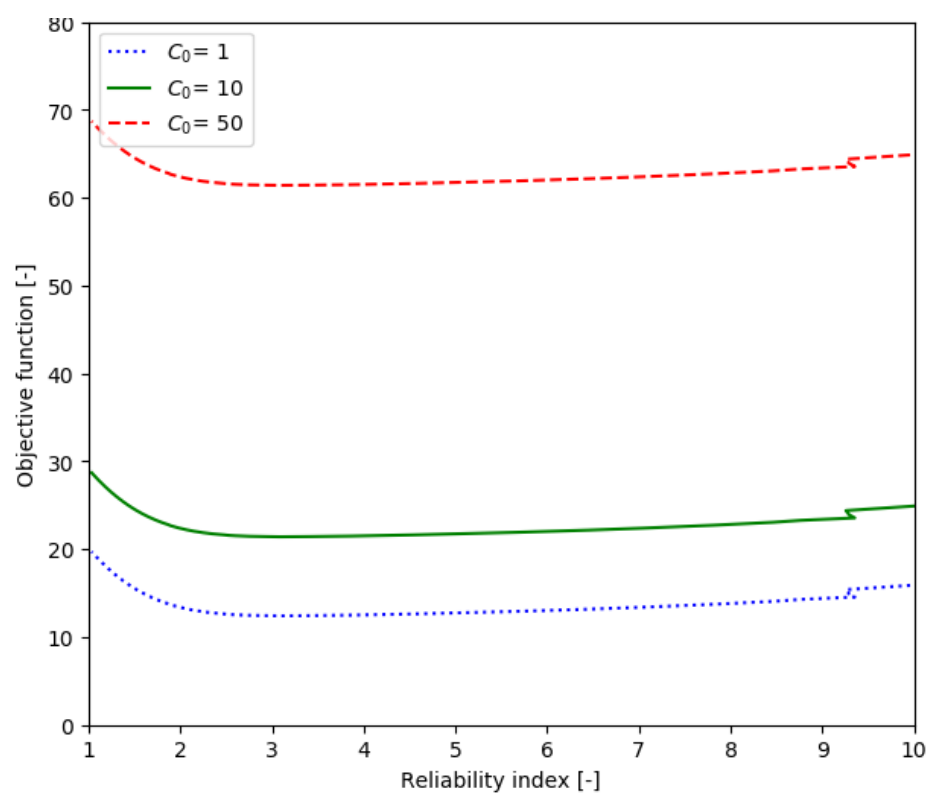

Figure 4. Objective function $Z$ in function of $\beta$ for different values of the initial cost $C_{0}$ (scaffold of class 3 , transoms of $0.73 \mathrm{~m}, \gamma=0.02$ and $\xi=1$ )

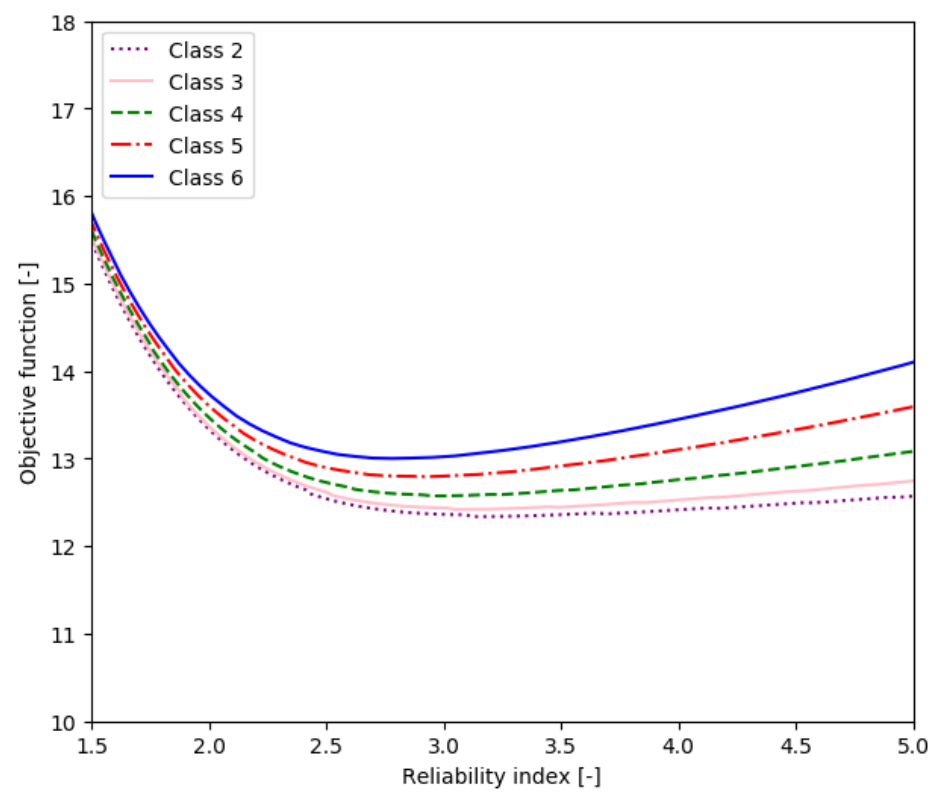

Figure 5. Objective function $Z$ in function of $\beta$ for different scaffold classes (transoms of 0.73 $\mathrm{m}, C_{0}=1, \gamma=0.02$ and $\left.\xi=1\right)$

The same procedure as described above is also performed for the limit state of flexural buckling. These calculations result in a similar behaviour of the objective function $Z$ and the same conclusions can be derived from this. Considering the results presented above, it is concluded that the assumptions on the different parameters only slightly influence the required safety level. Since it is for example difficult to accurately estimate the ratio of the failure cost to the initial construction cost for scaffolds, the observed behaviour is beneficial. For economical considerations, target reliabilities in the range of 2.5 to 3.5 can be proposed. However, the target reliability index can be determined more accurately considering casespecific aspects (e.g. scaffold class) and more detailed information on the discount rate and costs. Nevertheless it should be noted that, in any case, a target reliability index of at least 2.3 must be respected, considering human safety evaluation as explained above. 


\subsection{Conclusion on the target reliability level}

Based on literature, three values are proposed for the target reliability index considering human safety requirements: 2.3, 2.9 and 3.1. Looking at economic optimisation, the minimum of the objective function varies depending on the assumed value of the ratio of the failure cost to the initial cost $\xi$, the discount rate $\gamma$ and scaffold class, among others. Here, the most influencing parameter is the ratio of the failure cost to the initial cost $\xi$. When changing this, the reliability index corresponding to the absolute minimum of the objective function varies between 2.5 and 3.5. Nevertheless, as shown in the previous, in general the objective function is quite constant around its minimum, thus slightly higher values of $\beta$ could also lead to a feasible optimal solution from an economical point of view. Hence, the target value of the reliability index for human safety requirements and economic optimisation are situated in the same range. For the determination of the partial factors in the following, three values for the target reliability level are assumed: $\beta_{t}=2.5, \beta_{t}=3.0$ and $\beta_{t}=3.5$. It must be emphasised that these are target reliabilities for a reference period of one year. It should also be pointed out that these target reliabilities differ from those for permanent structures for a reference period of one year. This can be ascribed to the difference in construction costs and failure costs between these different types of structures, leading to a different economic optimisation.

\section{Optimisation of partial factors for temporary structures}

\subsection{Reference model}

As a reference model, a scaffold with a total length of $20.7 \mathrm{~m}$ (10 sections of $2.07 \mathrm{~m})$ and a width of $1.09 \mathrm{~m}$ is modelled in a commercial direct stiffness method based calculation tool (i.e. beam finite element software including a package specifically for the design of scaffolds) (Figure 6). The scaffold has a height of $11 \mathrm{~m}$ (5 floors of $2 \mathrm{~m}+$ a guardrail of $1 \mathrm{~m}$ ). The connections between the standards are modelled as rigid. The floorboards are $32 \mathrm{~cm}$ wide and have an average weight of $8.20 \mathrm{~kg} / \mathrm{m}$. The connections between the floorboards and the ledgers are modelled as hinged in the local y-direction and rigid in the other directions. The bracings also have hinged connections in the local y-direction at both ends. The connections between the standards and the ledgers are assumed to be of the type Layher Variante K2000+ (Layher, 2018). Anchorage points, simulating the anchorage in the façade, are positioned every two floors. The lower supports at the contact with the ground are modelled as described in EN 12811-1 (CEN, 2004). This means that all translations are fixed and the point of support is modelled as a bilinear spring, with a rotation stiffness of $20,000 \mathrm{Nm} / \mathrm{rad}$ for the angle between the base jack and the ground.
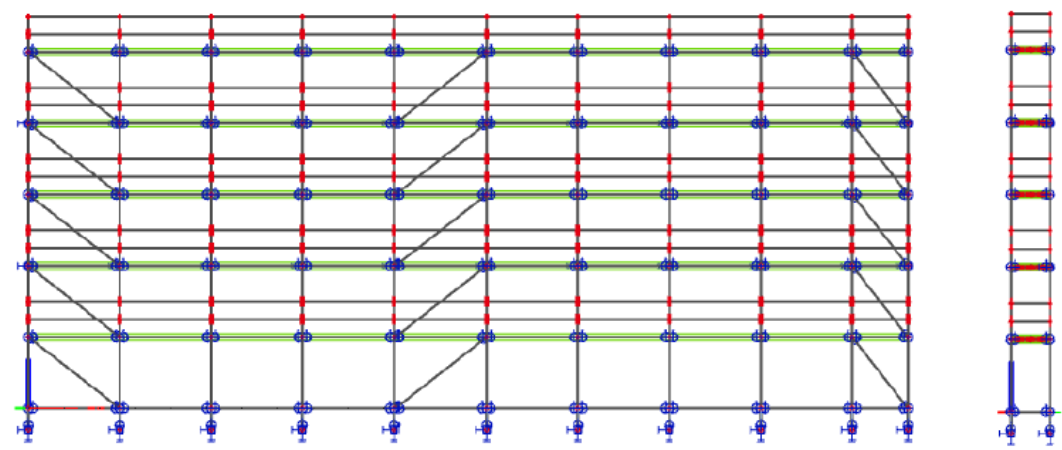

Figure 6. First model of an unclad scaffold 
The scaffolds are designed in the ultimate limit state (ULS) as such to fulfil the requirements as optimal as possible. Therefore, as a scaffold of class 3 is assumed, a uniformly distributed imposed load of $2 \mathrm{kN} / \mathrm{m}^{2}$ is applied to the top level and $1 \mathrm{kN} / \mathrm{m}^{2}$ to the level just below for the service condition, together with a working wind load of $0.2 \mathrm{kN} / \mathrm{m}^{2}$. For the outof-service condition, $25 \%$ of this uniformly distributed imposed load is applied, together with the maximum wind. The results of the ULS calculations show that one of the lower standards (i.e. a vertical element at one of the lower levels of the scaffold) is the one with the largest unity check for buckling. Stresses on the other hand, are critical for a transom on the highest floor. The in-service condition with wind perpendicular to the façade is the most determining load combination for both buckling and yielding. As stated in section 2.1, this service condition is the load case where the service load is applied on the most critical level together with a working wind load (velocity pressure of $0.2 \mathrm{kN} / \mathrm{m}^{2}$ ).

\subsection{Probabilistic models and calculation scheme}

This section presents the methodology used to determine the reliability index of temporary structures. This methodology is based on numerical simulations and probabilistic calculations, performed for several possible scaffold designs. The structural calculations of scaffolds are performed using a package specific for scaffold design in the commercial direct stiffness method based calculation tool. The models simulated in this calculation tool are used to perform the probabilistic calculations for which probabilistic models are assigned to different parameters in the scaffold design.

The following variables are considered:

- The density $\rho_{\text {tubes }}$ and dimensions (thickness $t$ and diameter $D$ ) of the scaffold tubes;

- The density of the floorboards $\left(\rho_{F B}\right)$;

- The Young's modulus $E$ and yield strength $f_{y}$ of the scaffold tubes;

- The initial bow imperfection $v_{0}$ of the elements;

- The wind load $W$ (characterised by the time invariant component of the wind action $C_{0, w}$ and the annual maxima of the basic wind velocity $v_{b}$ ) and imposed load $Q$.

The mean values of the dimensions $D$ and $t$ are based on the characteristic values mentioned in EN 12811-1 (CEN, 2004): tubes with outer diameter $D=48.3 \mathrm{~mm}$ and tube thickness $t=3.2 \mathrm{~mm}$. The coefficients of variation are based on the coefficient of variation for the cross-section $A$ according to (Cajot et al., 2005), prescribing an upper value of 0.04 . Considering $V_{A}=0.04$ and $V_{D}=V_{t}$, and using a Taylor approximation $V_{D}=V_{t}=0.028$. The permanent load on scaffolds consists of the self-weight of the elements (tubes and floorboards). The variation of the density of the steel tubes is considered by assigning a normal distribution with as mean value the characteristic value $\left(7850 \mathrm{~kg} / \mathrm{m}^{3}\right)$ and a coefficient of variation of 0.02 , based on (JCSS, 2001). For permanent loads, the same reference prescribes a coefficient of variation of 0.1 . Since the floorboards are no structural elements in the probabilistic calculations, they are implemented as permanent loads working on the transoms. Therefore, a normal distribution with mean value equal to the characteristic value $\left(640.6 \mathrm{~kg} / \mathrm{m}^{3}\right)$ and a COV of 0.1 is assumed for the self-weight of the floorboards. According to EN 12811-1 (CEN, 2004), scaffold tubes have a steel quality S235 with a characteristic value $f_{y, k}=235 \mathrm{MPa}$. For the Young's modulus of the steel, a value of $200 \mathrm{GPa}$ is considered. The probabilistic models of the steel properties $\left(f_{y}\right.$ and $E$ ) are based on the Probabilistic Model Code (PMC) of JCSS (JCSS, 2001). The model for the initial bow imperfection is adopted from (Zhang, Rasmussen, \& Ellingwood, 2012). The initial curvature of the tubes is assumed to be larger than zero, since the reuse of scaffold elements can lead to an out-of-straightness (Zhang, Chandrangsu, \& Rasmussen, 2010). For the wind load, both a time-variant and a time-invariant contribution are considered. The wind load for a reference period of one year can be written as $W=C_{k} C_{0 w} v_{b}^{2}$ (Caspeele et al., 2016; Caspeele, Sykora, Allaix, \& Steenbergen, 2013). Here, $C_{k}$ is equal to the 
wind pressure $q_{p}$ (as calculated according to EN 1991-1-4) divided by the characteristic value of the basic wind speed $v_{b, k}$ squared $\left(C_{k}=q_{p} / v_{b, k}^{2}\right)$. Hence, $C_{k}$ represents the product of different time-invariant coefficients in the calculation of the wind pressure. Its variability is represented by $C_{O w}$, to which a lognormal distribution with mean 0.65 and a coefficient of variation of 0.3 is assigned. The time-varying part of the wind pressure, is taken into account by the annual maxima of the basic wind velocity $v_{b}$, modelled by a Gumbel distribution with mean $0.72 v_{b, k}$ and a coefficient of variation of 0.15 . The characteristic value of the basic wind speed $v_{b, k}$ is taken equal to $25 \mathrm{~m} / \mathrm{s}$. This basic wind velocity is defined according to EN1991-14 as the fundamental basic wind velocity modified to account for seasonal and directional effects, where the fundamental basic wind velocity is the mean wind velocity for a 10 minute averaging period with an annual probability of being exceeded of 0.02 , at a height of $10 \mathrm{~m}$ above ground level in flat open country terrain. For the imposed load a Gumbel distribution was proposed by Cajot et al. (2005), with a value of $0.21 Q_{k}$ for the standard deviation. The mean value is based on the assumption that the characteristic value is the $95 \%$-fractile of the Gumbel distribution with a reference period of 50 years, resulting in a mean value of $0.2312 Q_{k}$. The characteristic value of the imposed load $Q_{k}$ varies depending on the scaffold class $\left(0.75 \mathrm{kN} / \mathrm{m}^{2}\right.$ for the lowest class and $6 \mathrm{kN} / \mathrm{m}^{2}$ for the highest class). The fraction of this load that should be applied depends whether the in-service or the out-of-service condition is considered, as explained in section 2.1. Since for five years the load will remain constant, the mean for $t_{r e f}=5$ years could be adopted for a reference period of one year as well. The variables considered, as well as their respective distribution, mean value $\mu$ and coefficient of variation $V$, are summarised in Table 4. It should be pointed out that the initial bow imperfection $v_{0}$ is a function of the element length $L$.

Table 4. Variables and their assigned probabilistic model

\begin{tabular}{llll}
\hline Variable & Distribution & Mean $\boldsymbol{\mu}$ & COV $\boldsymbol{V}$ \\
\hline$t[\mathrm{~mm}]$ & Lognormal & 3.2 & 0.028 \\
$D[\mathrm{~mm}]$ & Lognormal & 48.3 & 0.028 \\
$\rho_{\text {tubes }}\left[\mathrm{kg} / \mathrm{m}^{3}\right]$ & Normal & 7850 & 0.02 \\
$\rho_{\mathrm{FB}}\left[\mathrm{kg} / \mathrm{m}^{3}\right]$ & Normal & 640.6 & 0.10 \\
$f_{\mathrm{y}}[\mathrm{MPa}]$ & Lognormal & 244 & 0.07 \\
$E[\mathrm{MPa}]$ & Lognormal & 200000 & 0.03 \\
$Q\left[\mathrm{kN} / \mathrm{m}^{2}\right]$ & Gumbel & $0.2312 Q_{k}$ & 0.91 \\
$C_{0, \mathrm{w}}[-]$ & Lognormal & 0.65 & 0.30 \\
$v_{\mathrm{b}}[\mathrm{m} / \mathrm{s}]$ & Gumbel & 18 & 0.15 \\
$v_{0}[\mathrm{~mm}]$ & Lognormal & $L / 770$ & 0.6 \\
\hline
\end{tabular}

For each of the variables in Table 4, 40 samples are generated using Latin Hypercube Sampling with reduced correlation (CLHS), which are subsequently used as input for the structural calculations in the calculation tool. From these simulations, for each element of the scaffold 40 values of the internal forces, stresses and buckling lengths are obtained. Subsequently, distributions are fit to the latter values, representing load effects and resistances. For the stresses, a Gumbel distribution is assumed as the stresses are predominantly the result of the service load $Q$, which also follows a Gumbel distribution. For the normal forces, bending moments and buckling coefficients a lognormal distribution is found to be appropriate. These distributions are inserted in limit state equations (2), (3) and (4), which are considered for the structural reliability calculations. These limit state equations represent failure due to yielding (equation (2)), interaction between normal forces and bending moments (equation (3)) and 
flexural buckling (equation (4)), respectively. FORM analyses are executed to derive the inherent reliabilities of the scaffold elements for these three different limit states. As such, element reliabilities are obtained.

$$
\begin{gathered}
g(\underline{X})=f_{y}(\underline{X})-\theta_{\sigma} \cdot \sigma(\underline{X}) \\
g(\underline{X})=1-\theta_{i} \cdot i(\underline{X}) \\
g(\underline{X})=\theta_{b} \cdot N_{R}(\underline{X})-\theta_{N} \cdot N(\underline{X})
\end{gathered}
$$

The buckling resistance $N_{\mathrm{R}}$ and interaction $i$ are calculated using equations (5) and (6) respectively.

$$
\begin{gathered}
N_{R}=\chi \cdot A \cdot f_{y} \\
i=\frac{N}{N_{R}}+\frac{1}{1-\frac{N}{N_{c r}}} \frac{N \cdot v_{0}}{M_{p l}}+\frac{M}{M_{p l}} \leq 1
\end{gathered}
$$

The model uncertainties $\theta$ considered are the following (with $\mathrm{LN}$ a lognormal distribution):

- $\theta_{\sigma}: \mathrm{LN}(\mu=1 ; \sigma=0.1)$, as the stresses are predominantly induced by bending moments ('JCSS, 2001);

- $\theta_{N}: \mathrm{LN}(\mu=1 ; \sigma=0.05)(\mathrm{JCSS}, 2001)$;

- $\theta_{i}: \mathrm{N}(\mu=1.31 ; \sigma=0.10)$ (Cajot et al., 2005).

Since only limited information on the model uncertainty $\theta_{b}$ for buckling is available in literature, this parameter is determined based on a fictitious scaffold column, loaded by a permanent and variable load (with $t_{r e f}=50$ years), designed considering different load ratios $(Q /(P+Q))$. The reliability index of this column is determined for different assumptions of the mean value of $\theta_{b}$. A lognormal distribution is considered for $\theta_{b}$. The coefficient of variation of the model uncertainty is taken from (Cajot et al., 2005) and equal to 0.075. Finally, the mean of $\theta_{b}$ is chosen as such that a reliability index of about 3.8 for the different load ratios is determined in accordance to EN 1990. Hence, a mean value of 1.35 is adopted in this study (see Figure 7).

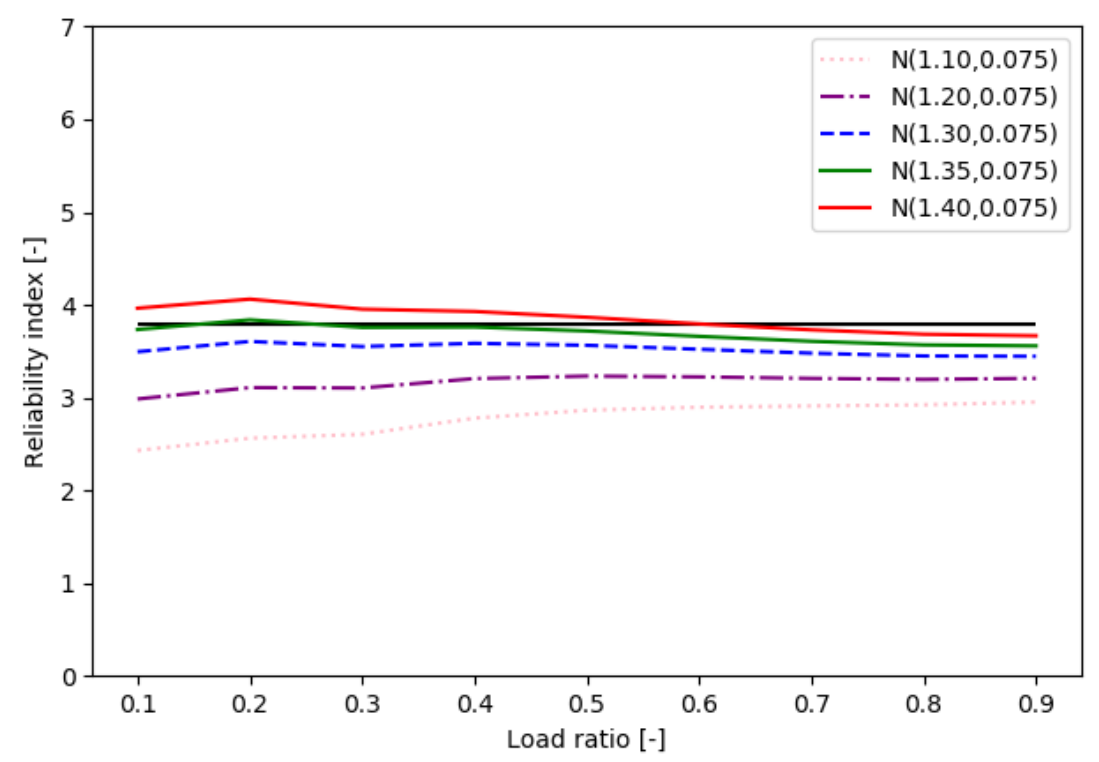

Figure 7. Influence of the load ratio and the model uncertainty of the buckling resistance on the lifetime reliability index $\beta_{50}$ determined for the limit state of flexural buckling for a scaffold standard subjected to loads with $t_{r e f}=50$ years

Finally, the calculation procedure as explained above is summarised in Figure 8. 


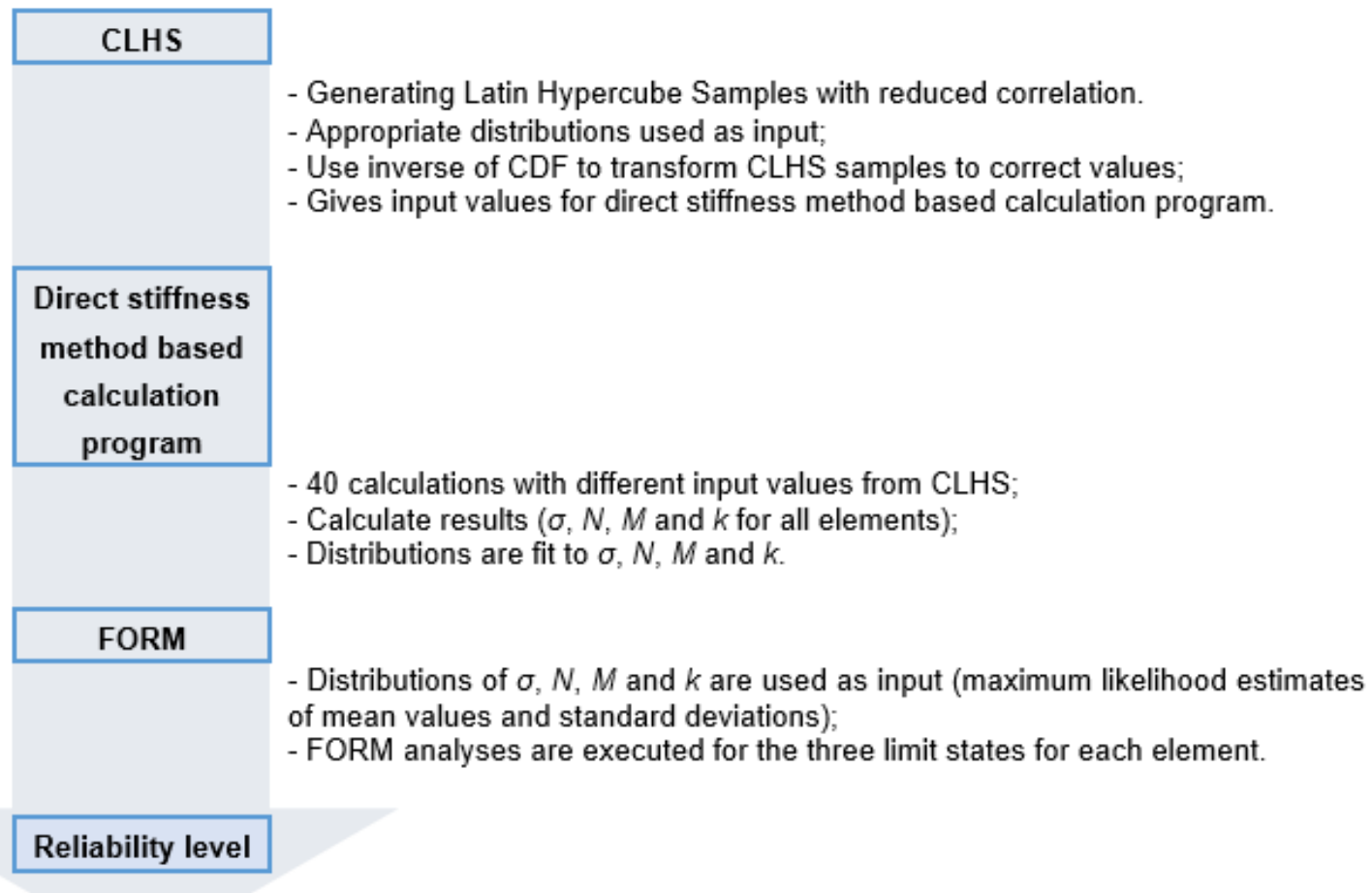

Figure 8. Schematic representation of the framework for structural reliability analyses of scaffold structures

\subsection{Optimisation procedure to determine partial factors}

The optimisation procedure which can be applied to determine the optimal set of partial factors $\gamma$ can be represented by formula (7).

$$
\min _{\gamma} W(\gamma)=\sum_{j=1}^{L} w_{j}\left(\beta_{j}(\gamma)-\beta_{t}\right)^{2}
$$

Here, $L$ is the number of design situations considered. In the current study, $L=16$ design situations are considered. The scaffolds considered are variations with respect to the reference scaffold. More specifically, the following design situations are considered in the optimisation procedure for the partial factors:

- The reference scaffold with jack extensions of $100 \mathrm{~mm}$ and $600 \mathrm{~mm}$;

- A scaffold with cladding applied to the scaffold faces (ledger length reduced to $1.57 \mathrm{~m}$, different anchorage pattern (see appendix));

- A scaffold of class 2 instead of class 3 (ledger length increased to $2.57 \mathrm{~m}$ );

- A scaffold of class 4 instead of class 3 (ledger length of $2.07 \mathrm{~m}$, transom length reduced to $0.73 \mathrm{~m}$ );

- A scaffold of class 5 instead of class 3 (ledger length reduced to $1.57 \mathrm{~m}$, transom length reduced to $0.73 \mathrm{~m}$ );

- A scaffold of class 6 instead of class 3 (ledger length reduced to $1.09 \mathrm{~m}$, transom length reduced to $0.73 \mathrm{~m}$ );

- Scaffolds extending above the building they are anchored in (clad and unclad) (see appendix);

- Scaffolds extending besides the building they are anchored in (clad and unclad) (see appendix);

- A scaffold with general connections according to EN 12811-1 (length of 6x2.07 m, height of $7 \mathrm{~m}$, width of $1.09 \mathrm{~m}$ );

- A scaffold with a cantilevering part (see appendix); 
- An indoor space scaffold (see appendix);

- Two small self-standing scaffolds (see appendix).

The weight factor $w_{j}$, representing the importance of each design, is set equal to $1 / 16$ for all values of $j$. For the determination of the partial factors, values $\beta_{t}=2.5,3$ and 3.5 are considered for the target reliability index.

Different sets of partial factors $\gamma$ are inserted in the optimisation function, considering different partial factors for the material properties $\left(\gamma_{M}\right)$, variable loads $\left(\gamma_{Q}, \gamma_{W}\right)$ and permanent loads $\left(\gamma_{G}\right)$. For $\gamma_{M}$, either a factor 1 or 1.1 is adopted. For the permanent loads, the factors 1 , 1.35 and 1.5 are considered. However, adjusting this partial factor has a negligible influence on the scaffold design. For the variable loads, the partial factors vary from 0.7 to 1.6 . It must be pointed out that the partial factors for the imposed loads and for the wind loads are taken equal, as also currently in the Eurocodes only one partial factor is given for all the variable loads. Furthermore, as the design of the scaffold itself was considered and no failure mechanisms related to failure of anchorage systems are involved, the wind load did not have a significant contribution to the failure mechanisms investigated in this paper.

The 16 design situations are re-evaluated for all sets of partial factors. Applying the procedure of Figure 8, the corresponding reliability levels are determined and are implemented in equation (7). As such, the optimal set of partial factors is determined, considering the constraints with respect to the considered partial factor combinations. The discrete points for the considered sets of partial factors are plotted, to which then a parabolic curve is fitted (see for example Figure 9 for $\beta_{t}=2.5$ ) and the minimum value is determined. Different graphs like the one in Figure 9 are constructed: graphs only considering unclad scaffolds of class 3, only clad scaffolds of class 3 , only anchored scaffolds of class 3 or only self-standing scaffolds (see Figure 10 to Figure 13). Hence, the partial factors are determined as such that for all these cases, the value of $W$ would be (close to its) minimum or on the conservative side. For $\beta_{t}=2.5$, this leads to the following partial factors: $\gamma_{M}=1, \gamma_{Q}=0.8$ and $\gamma_{G}=1.35$. For the graphs in Figure 9, this set of partial factors corresponds to the minimum of the data points plotted. However, the same value of $W$ is reached when changing $\gamma_{G}$ to 1.5 or 1 . However, keeping in mind the fact that designers are used to apply a factor of 1.35 for permanent actions in EN 1990, this factor might be practically preferable. The proposed set of partial factors is also (close to) optimal when looking at Figure 10 to Figure 13. When only considering the unclad scaffolds of class 3 (Figure 10), the minimum of the parabolic curves is reached for this combination of partial factors. Also for clad scaffolds of class 3 (Figure 11), self-standing scaffolds (Figure 12) and anchored scaffolds (Figure 13), this set of partial factors corresponds to the minimum value of the data points of $W$. 

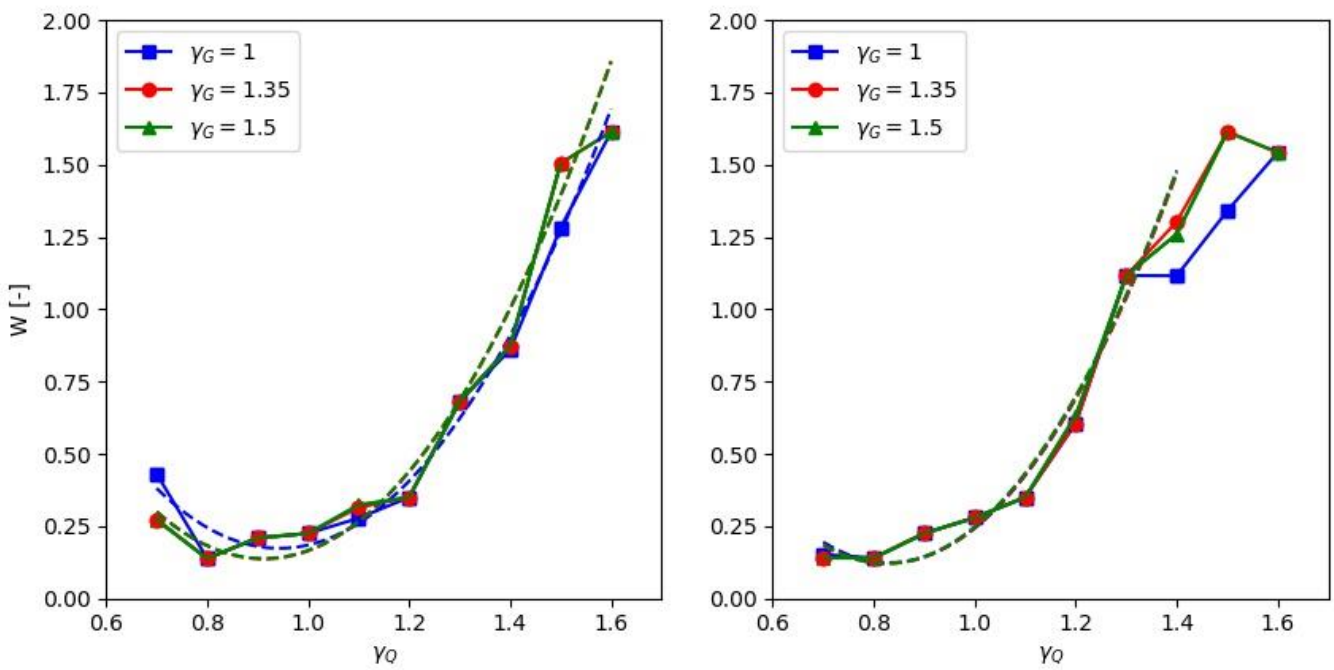

Figure 9. Optimisation function $W$ in function of $\gamma_{Q}$ for different values of $\gamma_{G}$ and $\beta_{t}=2.5$ for $\gamma_{M}=1$ (left) and $\gamma_{M}=1.1$ (right)
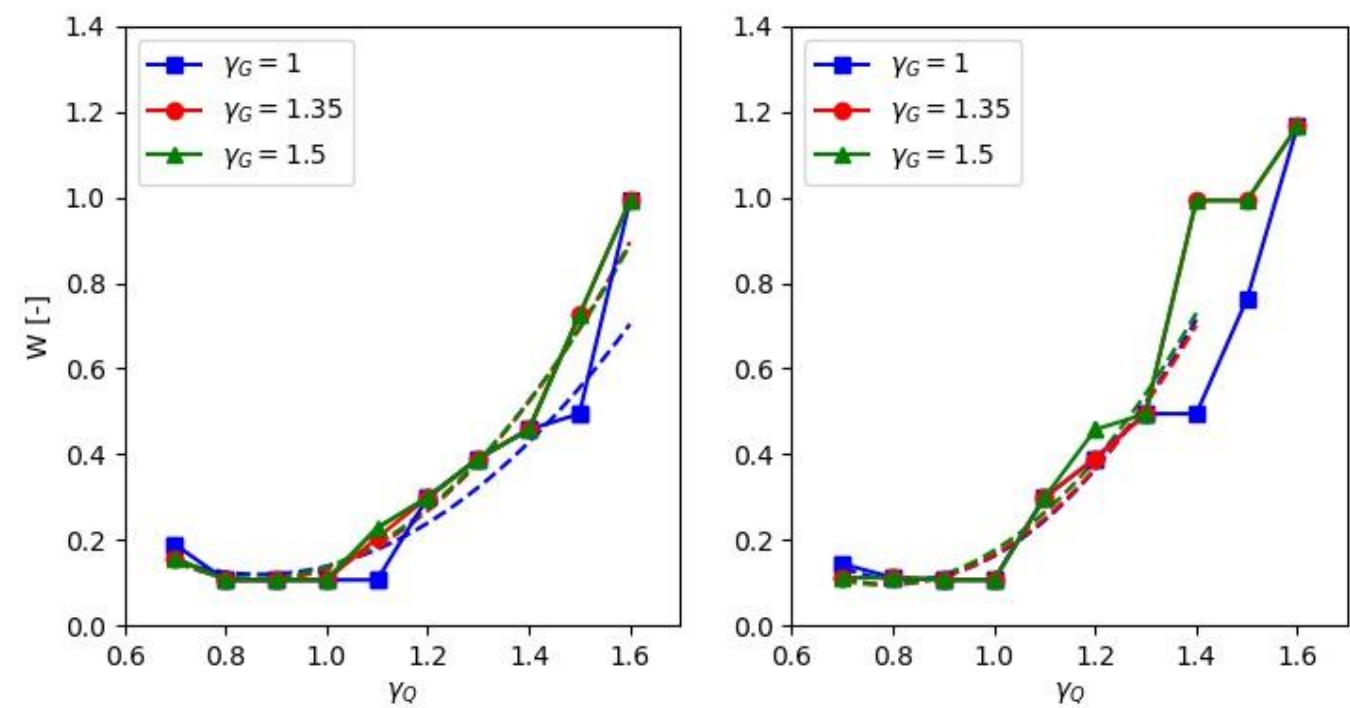

Figure 10. Optimisation function $W$ for $\beta_{t}=2.5$ and unclad scaffolds of class 3 , for $\gamma_{M}=1$ (left) and $\gamma_{M}=1.1$ (right) 

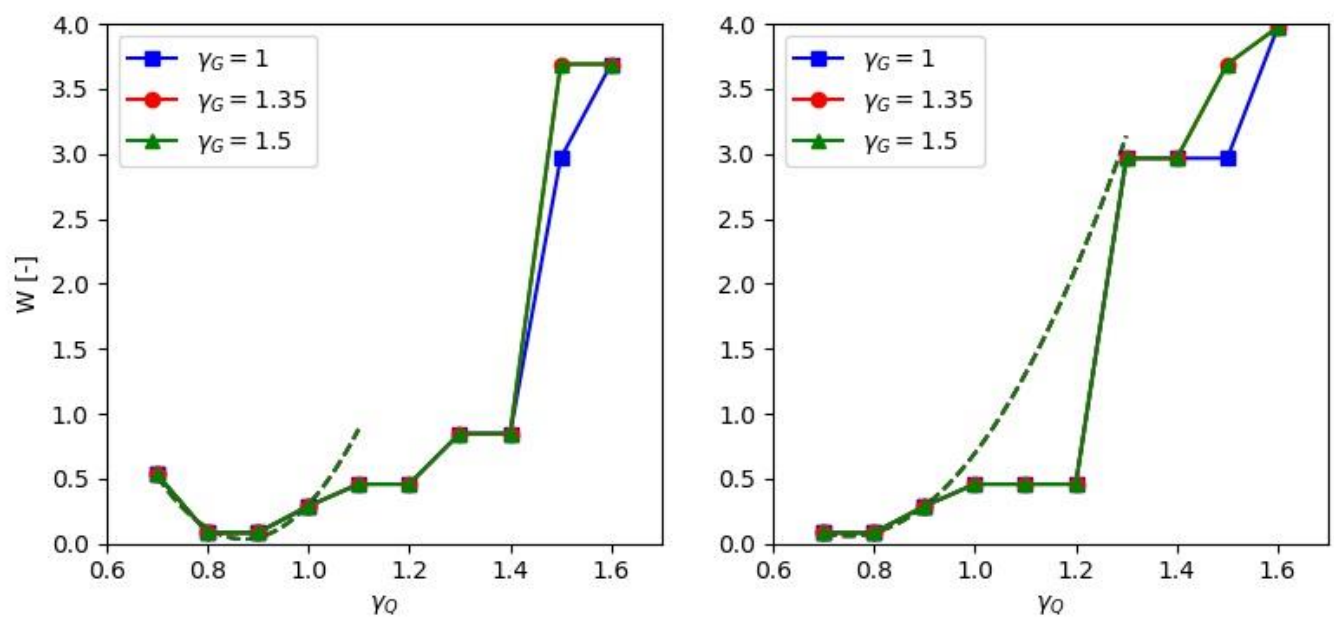

Figure 11. Optimisation function $W$ for $\beta_{t}=2.5$ and clad scaffolds of class 3 , for $\gamma_{M}=1$ (left) and $\gamma_{M}=1.1$ (right)
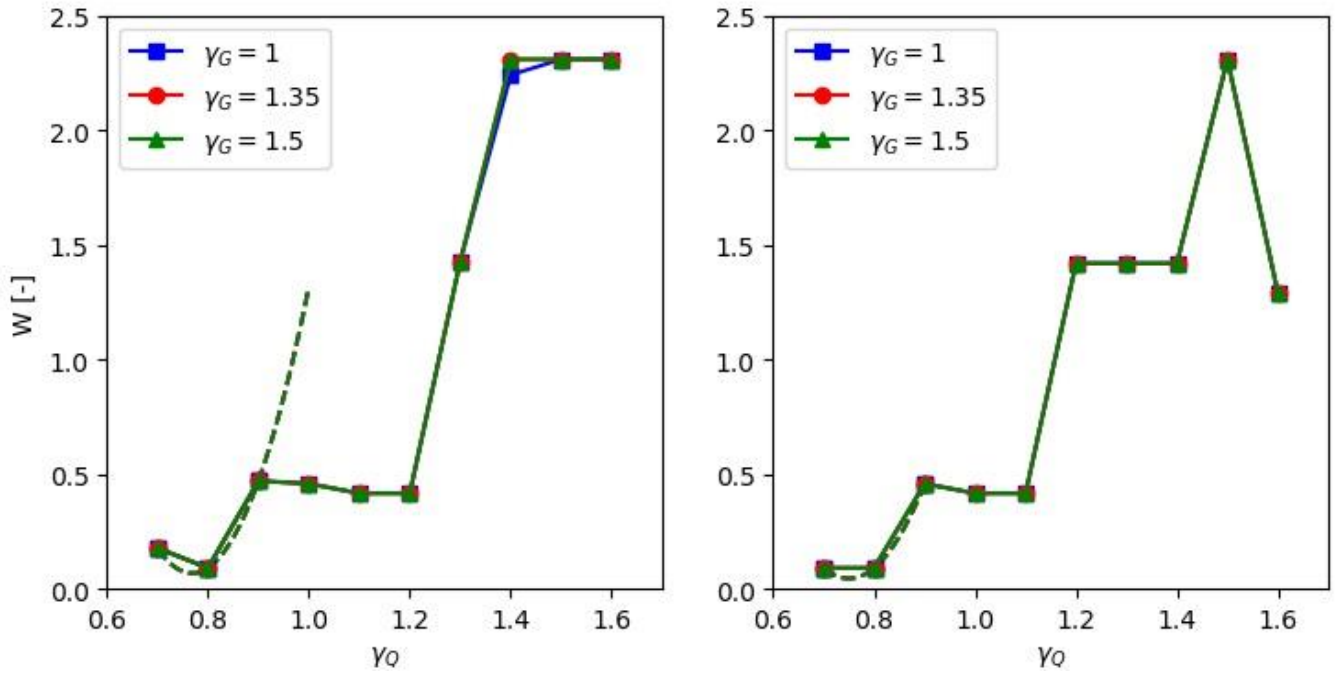

Figure 12. Optimisation function $W$ for $\beta_{t}=2.5$ and self-standing scaffolds, for $\gamma_{M}=1$ (left) and $\gamma_{M}=1.1$ (right) 

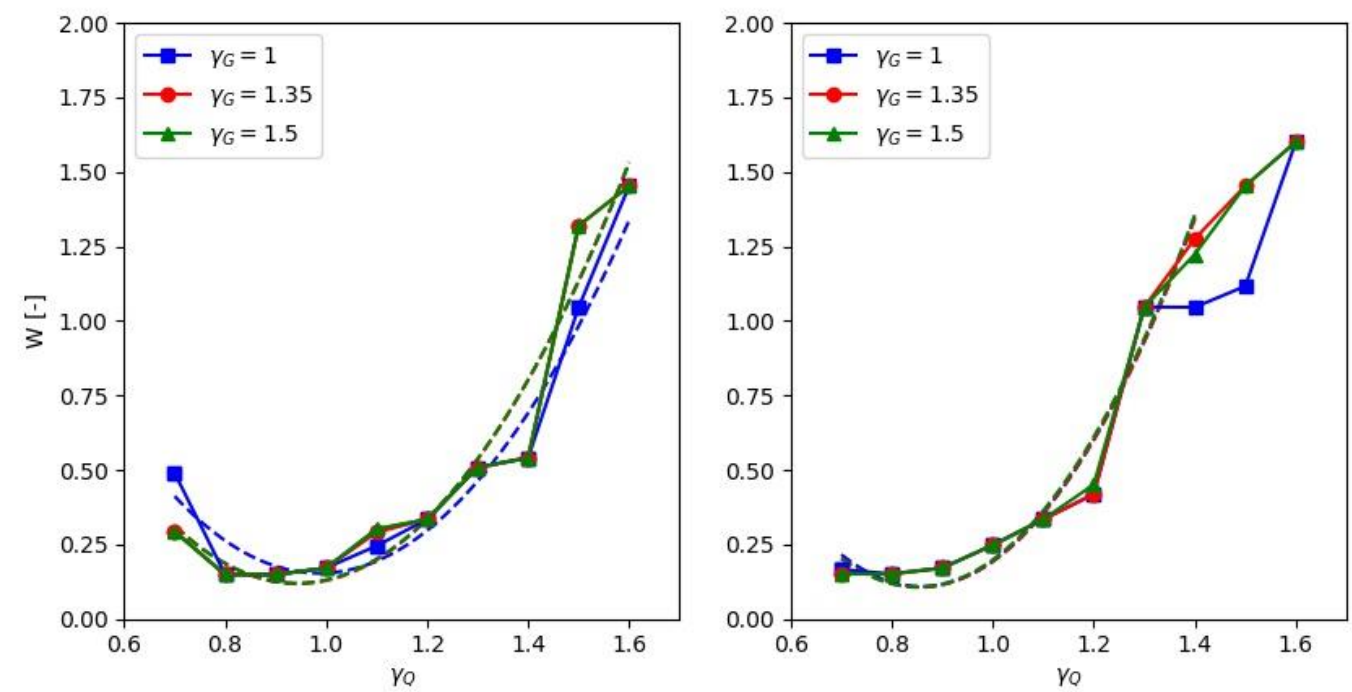

Figure 13. Optimisation function $W$ for $\beta_{t}=2.5$ and anchored scaffolds, for $\gamma_{M}=1$ (left) and $\gamma_{M}=$ 1.1 (right)

Recommended partial factors, based on the discussion above, for the three considered target reliabilities, are summarised in Table 5.

Table 5. Optimal sets of partial factors for different target reliability levels, obtained using the optimisation procedure

\begin{tabular}{l|llll}
\hline & $\gamma_{G}$ & $\gamma_{Q}$ & $\gamma_{W}$ & $\gamma_{M}$ \\
\hline $\boldsymbol{\beta}_{\boldsymbol{t}}=\mathbf{2 . 5}$ & 1.35 & 0.80 & 0.80 & 1.00 \\
$\boldsymbol{\beta}_{\boldsymbol{t}}=\mathbf{3 . 0}$ & 1.35 & 1.20 & 1.20 & 1.00 \\
$\boldsymbol{\beta}_{\boldsymbol{t}}=\mathbf{3 . 5}$ & 1.35 & 1.40 & 1.40 & 1.10 \\
\hline
\end{tabular}

When one would consider partial factors for the wind loads and imposed loads separately, the values of the optimization function $W$ will only be slightly adapted. The optimal set of partial factors will still lie close to the ones suggested above. For example, the optimal partial factor for the wind loads for a target reliability of 3 will vary between 1.0 and 1.2, depending whether the scaffolds are clad or unclad. Considering all possible scaffold configurations, partial factors of 1.2 for both service loads and wind loads are still an optimal solution. Similar conclusions can be drawn for the other target reliabilities.

\subsection{Suggested partial factors on the basis of the Adjusted Partial Factor Method (APFM)}

In the Adjusted Partial Factor Method (APFM), adjustment factors $\omega_{\gamma}$ are defined as such that $\gamma_{x, \text { new }}=\omega_{\gamma} \gamma_{x, \text { orgininal. }}$. Here, $\gamma_{x, \text { new }}$ is the partial factor to be calculated and $\gamma_{x, \text { original }}$ is the factor as currently found in EN 12811-1. This method was originally developed for the assessment of existing structures and the formulas indicated below are adopted from fib Bulletin 80 (Caspeele et al., 2016) and (Caspeele et al., 2013).

The adjustment factor for material properties is generally given by Equation (8), assuming a lognormal distribution for the material property.

$$
\omega_{\gamma_{M}}\left(\beta_{t}, V_{M}\right)=\frac{\gamma_{R d}\left(\beta_{t}\right)}{\gamma_{R d}\left(\beta^{\prime}\right)} \exp \left(\alpha_{R} \beta^{\prime} V_{M}^{\prime}\left(\frac{\beta_{t}}{\beta^{\prime}} \frac{V_{M}}{V_{M}^{\prime}}-1\right)\right)
$$


Here, $\beta_{t}$ is the target reliability index and $\beta$ ' is the reliability index inherently found in the structure when designing according to the partial factors currently found in EN 12811-1. The reliability index $\beta$ ' is determined according to the procedure from Figure 8 . $V_{M}$ is the coefficient of variation of the material properties, where the prime' again indicates the values assumed in the original design according to EN 12811-1. Since no information related to the value of $V_{M}$ ' used in EN 12811-1 is available, both COV's are assumed to be equal so $V_{M}=V_{M}$ '. The partial factor $\gamma_{R d}$ representing the resistance model uncertainty is a product of two contributions, namely the model uncertainty on the resistance model, $\gamma_{R d 1}=1 /\left(1-\alpha_{R} 0.4 \beta V_{\theta R}^{\prime}\right)$, and a contribution of the geometrical uncertainties, $\gamma_{R d 2}=1 /\left(1-\alpha_{R} 0.4 \beta V_{\theta g}^{\prime}\right)$, as also given in fib Bulletin 80 (Caspeele et al., 2016) and (Caspeele et al., 2013). The sensitivity factor for the resistances $\alpha_{R}$ is equal to 0.8 and $V_{\theta R d}$ represents the coefficient of variation of the resistance model uncertainty. The coefficient of variation representing geometric uncertainties $V_{\theta g}$ can be found by a calibration procedure based on the values of the partial factors prescribed by EN 12811-1. $V_{\theta g}$ can be written as a function of $\gamma_{R d 2}$ and the value of $\gamma_{R d 2}$ that should be used can be derived from the values of the partial factors found in EN 12811-1 ( $\left.\gamma_{M}=1.1\right)$ according to equation (9).

$$
\gamma_{R d}=\gamma_{R d 1} \gamma_{R d 2}=\frac{\gamma_{M}}{\gamma_{m}}=\frac{1.1 \exp \left(-0.8 \beta^{\prime} V_{M}^{\prime}\right)}{\exp \left(-1.645 V_{M}^{\prime}\right)}
$$

Finally, the partial factor for the material properties is calculated as $\gamma_{M}=\omega_{\gamma M} \cdot 1.1$.

For the permanent actions, the adjustment factor is given by Equation (10), based on a normal distribution for the permanent actions.

$$
\omega_{\gamma_{G}}\left(\beta_{t}, V_{G}\right)=\frac{\gamma_{E d, G}\left(\beta_{t}\right)}{\gamma_{E d, G}\left(\beta^{\prime}\right)} \frac{1-\alpha_{E} \beta_{t} V_{G}}{1-\alpha_{E} \beta^{\prime} V_{G}^{\prime}}
$$

Also here, 'refers to the values according to current design guidelines and the COV's are taken equal in both cases. The sensitivity factor for the load effects is equal to -0.7. The partial factor representing the model uncertainties is given as $\gamma_{E d, G}=1-\alpha_{E} 0.4 \beta V_{\theta G}$, where $V_{\theta G}$ can again be calculated based on a calibration procedure, similar as described above. It is calibrated to the partial factor $\gamma_{G}=1.5$ found in EN 12811-1. Finally, the partial factor for the permanent actions can be determined by applying $\gamma_{G}=\omega_{\gamma G} \cdot 1.5$.

The imposed loads are assumed to follow a Gumbel distribution. Hence, their adjustment factor is given by equation (11).

$$
\omega_{\gamma_{Q}}\left(\beta_{t}, V_{Q}\right)=\frac{\gamma_{E d, Q}\left(\beta_{t}\right)}{\gamma_{E d, Q}\left(\beta^{\prime}\right)} \frac{1-V_{Q}\left[0.45+0.78 \ln \left(-\ln \left(\Phi\left(-\alpha_{E} \beta_{t}\right)\right)\right)\right]}{1-V_{Q}^{\prime}\left[0.45+0.78 \ln \left(-\ln \left(\Phi\left(-\alpha_{E} \beta^{\prime}\right)\right)\right)\right]}
$$

Here, the sensitivity factor of the load effects is again equal to -0.7 and $V_{Q}$ is the coefficient of variation for a 5-year reference period (as already mentioned also corresponding to a reference period of one year). This reference period of 5 years is inserted in the formula for the adjustment factor for imposed loads given in (Caspeele et al., 2013, 2016). The partial factor to be applied on the imposed loads is then given by $\gamma_{Q}=\omega_{\gamma Q} \cdot 1.5$.

Since the wind loads are also described by a Gumbel distribution, the procedure to calculate the adjusted partial factors for wind loads is similar to that of the imposed loads (see equation (12)) and $\gamma_{W}=\omega_{\gamma_{W}} \cdot 1.5$.

$$
\omega_{\gamma_{W}}\left(\beta_{t}, V_{W}\right)=\frac{\gamma_{E d, W}\left(\beta_{t}\right)}{\gamma_{E d, W}\left(\beta^{\prime}\right)} \frac{1-V_{W}\left[0.45+0.78 \ln \left(-\ln \left(\Phi\left(-\alpha_{E} \beta_{t}\right)\right)\right)\right]}{1-V_{W}^{\prime}\left[0.45+0.78 \ln \left(-\ln \left(\Phi\left(-\alpha_{E} \beta^{\prime}\right)\right)\right)\right]}
$$

The COV's used in the equations mentioned above are summarised in Table 6. Here, the COV of the permanent loads is taken equal to the COV of the density of the floorboards, as this is more dominant compared to the self-weight of the tubes. The COV of the imposed load is taken equal to the one mentioned in Table 4. The COV for the wind load can be calculated based on the COV of the basic wind speed $\left(V_{v b}\right)$ according to $V_{W} \approx$ $V_{v b}\left(4-V_{v b}^{2}+6 V_{v b} \omega_{v b}\right)^{0.5} /\left(1+V_{v b}^{2}\right)$ (Caspeele et al., 2013, 2016). Here, $V_{v b}$ is set equal to 0.15 (Table 4) and the factor $\omega_{v b}$ represents the sample skewness, which can be taken equal to 
1.14 according to (Caspeele et al., 2013, 2016), since insufficient data is available. These assumptions lead to $V_{w}=0.33$. The COV of the material properties is the one assumed for the $E$-modulus in Table 4, as this leads to slightly higher values of the adjustment factor and is hence a little more conservative. Another option would be to define a different material factor for the $E$-modulus and the yield strength. Finally, the COV of the model uncertainty on the resistance is zero for the limit states of yielding and interaction and 0.075 for flexural buckling, as mentioned earlier.

Table 6. Coefficients of variations and their values assumed in the APFM

\begin{tabular}{ll}
\hline Parameter & Assumed value \\
\hline$V_{G}$ & 0.10 \\
\hline$V_{Q}$ & 0.91 \\
\hline$V_{W}$ & 0.33 \\
\hline$V_{M}$ & 0.03 \\
\hline$V_{\theta R}$ & 0.075 (buckling) \\
& 0 (interaction or yielding) \\
\hline
\end{tabular}

The value for the reliability index $\beta$ ' inherent to the current design procedure according to EN 12811 is the average reliability level obtained for all design situations considered in the optimisation procedure. For the design situations considered, a value of $\beta=3.59$ is obtained. Implementing this value and the COV's of Table 6 in the equations given above, results in the adaptation factors and corresponding partial factors as summarised in Table 7 for the three reliability levels assumed $\left(\beta_{t}=2.5,3.0\right.$ and 3.5). To achieve the adjustment factors for other target reliabilities, one can insert these target reliabilities in the equations given above or they can be read from the graphs as plotted in Figure 14 to Figure 17.

Table 7. Adjusted partial factors calculated with APFM

\begin{tabular}{cllllll}
\hline$\beta_{t}$ & \multicolumn{2}{l}{$\begin{array}{l}\text { Original } \\
\text { partial factor }\end{array}$} & \multicolumn{2}{l}{$\begin{array}{l}\text { Adjustment } \\
\text { factor }\end{array}$} & \multicolumn{2}{l}{$\begin{array}{l}\text { Adjusted } \\
\text { partial factor }\end{array}$} \\
\hline $\mathbf{2 . 5}$ & $\gamma_{G}$ & 1.5 & $\omega_{G}$ & 0.89 & $\gamma_{G}$ & 1.34 \\
& $\gamma_{Q}$ & 1.5 & $\omega_{Q}$ & 0.66 & $\gamma_{Q}$ & 0.99 \\
& $\gamma_{W}$ & 1.5 & $\omega_{W}$ & 0.72 & $\gamma_{W}$ & 1.08 \\
& $\gamma_{M}$ & 1.1 & $\omega_{M}$ & 0.96 & $\gamma_{M}$ & 1.05 \\
\hline $\mathbf{3 . 0}$ & $\gamma_{G}$ & 1.5 & $\omega_{G}$ & 0.94 & $\gamma_{G}$ & 1.41 \\
& $\gamma_{Q}$ & 1.5 & $\omega_{Q}$ & 0.80 & $\gamma_{Q}$ & 1.20 \\
& $\gamma_{W}$ & 1.5 & $\omega_{W}$ & 0.84 & $\gamma_{W}$ & 1.26 \\
& $\gamma_{M}$ & 1.1 & $\omega_{M}$ & 0.98 & $\gamma_{M}$ & 1.07 \\
\hline $\mathbf{3 . 5}$ & $\gamma_{G}$ & 1.5 & $\omega_{G}$ & 0.99 & $\gamma_{G}$ & 1.49 \\
& $\gamma_{Q}$ & 1.5 & $\omega_{Q}$ & 0.97 & $\gamma_{Q}$ & 1.45 \\
& $\gamma_{W}$ & 1.5 & $\omega_{W}$ & 0.97 & $\gamma_{W}$ & 1.46 \\
& $\gamma_{M}$ & 1.1 & $\omega_{M}$ & 0.996 & $\gamma_{M}$ & 1.10 \\
\hline
\end{tabular}




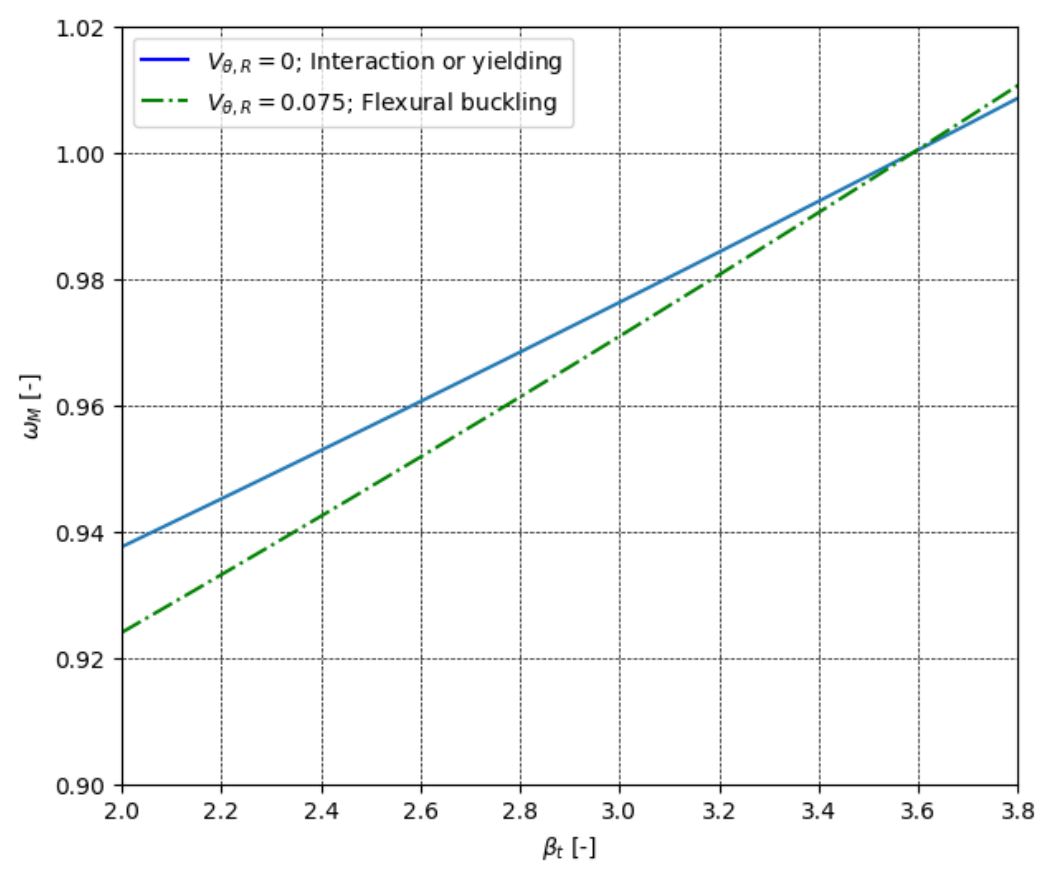

Figure 14. Adjustment factor $\omega_{M}$ as a function of the target reliability. The dashed lines indicate the target reliabilities chosen in this work $\left(\beta_{t}=2.5,3\right.$ and 3.5) and their corresponding adjustment factor $\left(\alpha_{R}=0.8, \beta{ }^{\prime}=3.59, V_{M}=V^{\prime}{ }_{M}=0.03\right)$

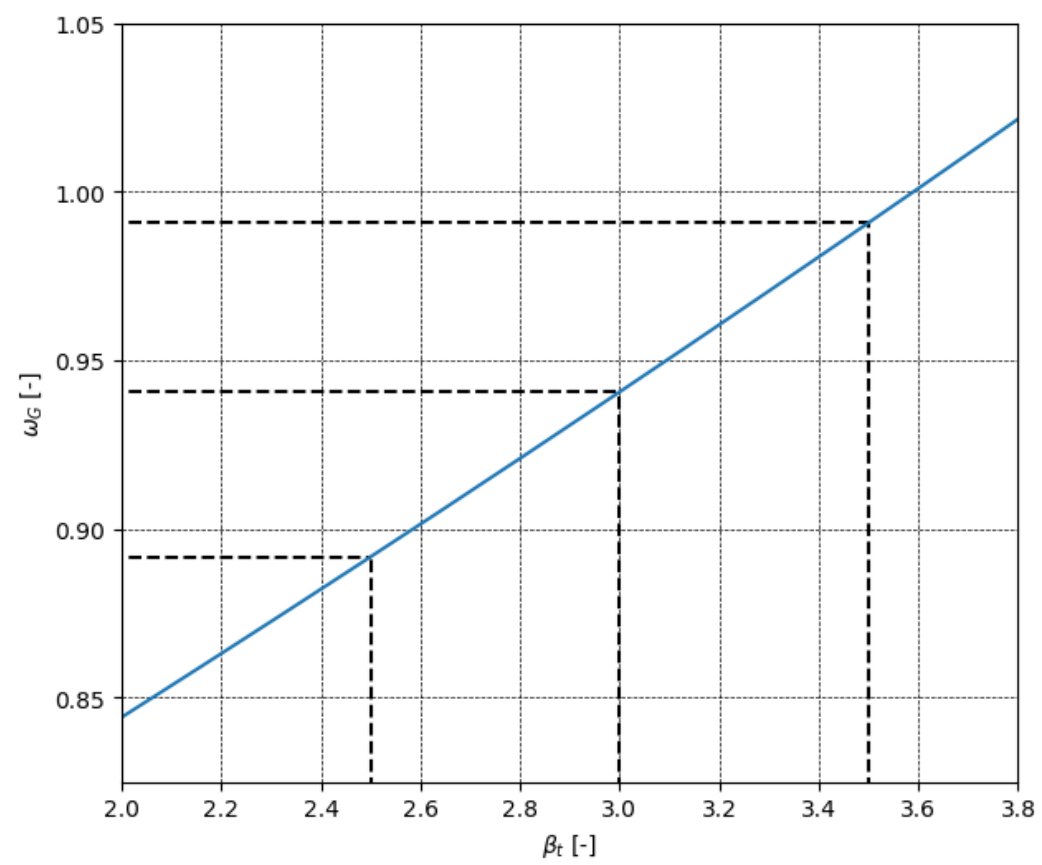

Figure 15. Adjustment factor $\omega_{G}$ as a function of the target reliability. The dashed lines indicate the target reliabilities chosen in this work $\left(\beta_{t}=2.5,3\right.$ and 3.5) and their corresponding adjustment factor $\left(\alpha_{E}=-0.7, \beta^{\prime}=3.59, V_{G}=V^{\prime}{ }_{G}=0.10\right)$ 


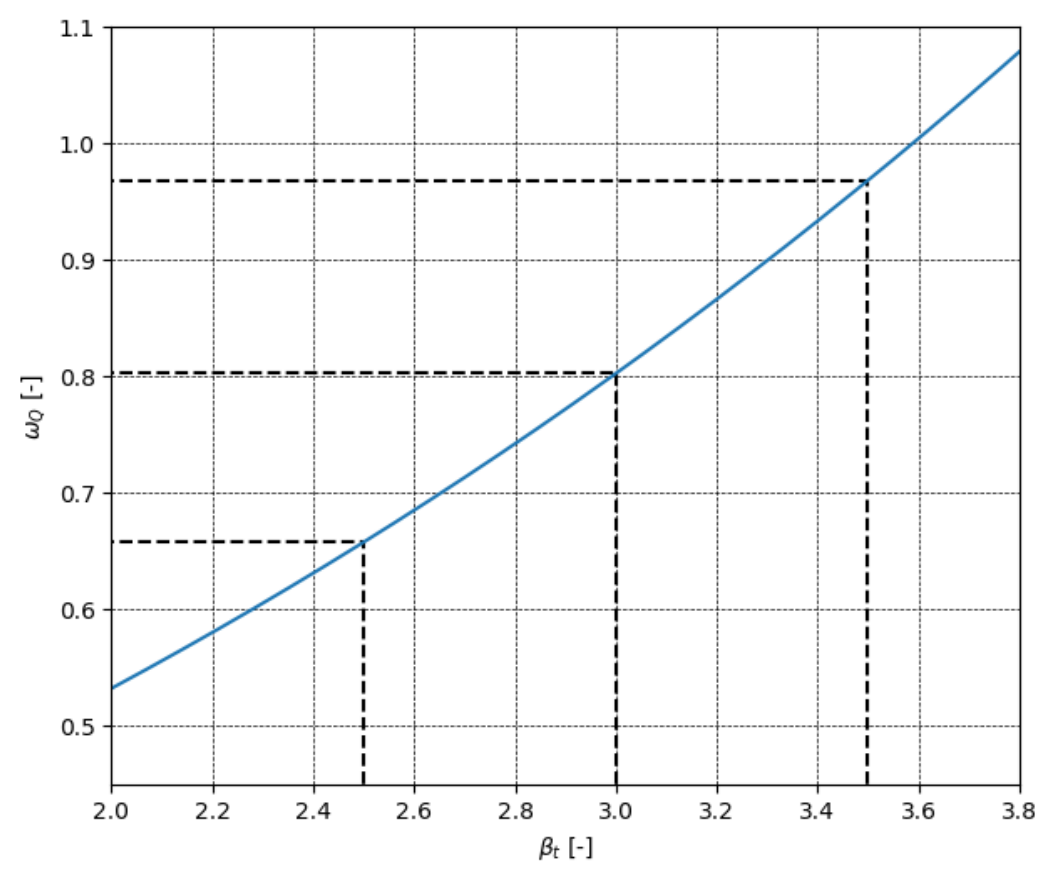

Figure 16. Adjustment factor $\omega_{Q}$ as a function of the target reliability. The dashed lines indicate the target reliabilities chosen in this work $\left(\beta_{t}=2.5,3\right.$ and 3.5) and their corresponding adjustment factor $\left(\alpha_{E}=-0.7, \beta{ }^{\prime}=3.59, V_{Q}=V^{\prime}{ }_{Q}=0.91\right)$

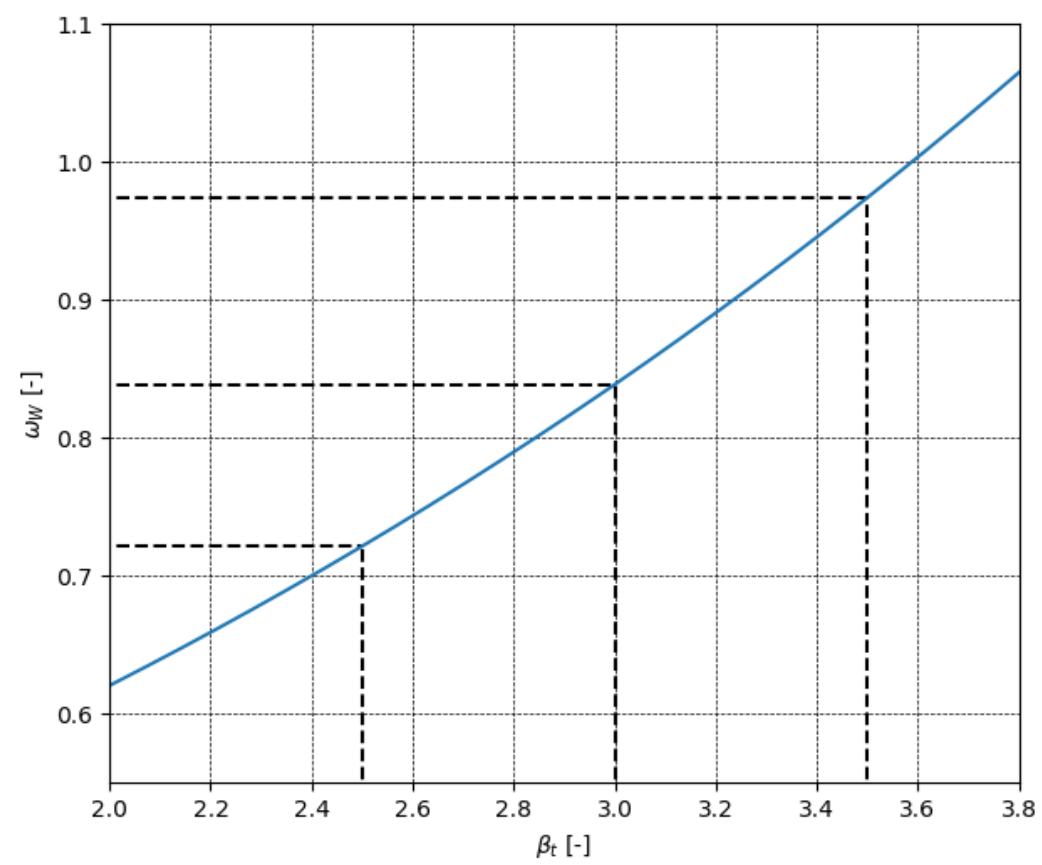

Figure 17. Adjustment factor $\omega_{W}$ as a function of the target reliability. The dashed lines indicate the target reliabilities chosen in this work $\left(\beta_{t}=2.5,3\right.$ and 3.5) and their corresponding adjustment factor $\left(\alpha_{E}=-0.7, \beta^{\prime}=3.59, V_{W}=V^{\prime}{ }_{W}=0.33\right)$

\subsection{Comparison partial factors obtained using the optimisation procedure and the APFM}

First of all, it should be kept in mind that both methods for the determination of partial factors are based on a different approach. The optimisation procedure aims at finding the optimal set of partial factors to achieve an overall reliability as close as possible to the target reliability for different scaffold designs. On the other hand, the starting point of the APFM are the partial 
factors currently found in EN 12811-1 and the inherent reliability level corresponding to these partial factors. Subsequently, the safety level is adapted to a desired target reliability level by applying adjustment factors to the original partial factors. This fundamental difference between the two methods should be kept in mind when comparing the two sets of partial factors.

In case of a target reliability level $\beta_{t}=2.5$, the partial factors for the permanent loads and for the material properties found by the two methods are comparable. For the permanent loads a partial factor of 1.35 can be proposed and $\gamma_{M}=1$ can be used for the material properties. For the variable loads a large difference between the two methods is obtained. However, for standardisation purposes, partial factors less than one are preferred to be replaced by $\gamma=1$. Accounting for this practical limitation, both methods would conclude a partial factor for the variable loads $\gamma_{Q}=1$. Comparing the different sets of partial factors found for $\beta_{t}=3$, a value of 1.2 for the partial factor for the variable loads appears to be appropriate. The influence of the partial factor for the permanent actions appeared to be negligible, so here $\gamma_{G}=1.35$ can be adopted in accordance to the optimisation procedure. At last, $\gamma_{M}=1.05$ can be proposed at the basis of the adjusted partial factor method, since this value is slightly more conservative than the one found with the optimisation procedure. Finally, in case of $\beta_{t}=3.5$, the target reliability level is almost equal to the mean of the different inherent reliabilities $\left(\beta^{\prime}=3.59\right)$. Therefore, it could be suggested to use the original partial factors as proposed in EN 12811-1 for $\beta_{t}=3.5$. The partial factors determined on the basis of the considered approaches are summarised in Table 8 for the different target reliability levels.

Table 8. Partial factors as determined on the basis of the considered approach (considering the results according to the APFM and optimisation procedure)

\begin{tabular}{l|lll}
\hline & $\boldsymbol{\beta}_{t}=\mathbf{2 . 5}$ & $\boldsymbol{\beta}_{\boldsymbol{t}}=\mathbf{3 . 0}$ & $\boldsymbol{\beta}_{\boldsymbol{t}}=\mathbf{3 . 5}$ \\
\hline$\gamma_{\boldsymbol{G}}$ & 1.35 & 1.35 & 1.50 \\
$\gamma_{Q}$ & 1.00 & 1.20 & 1.50 \\
$\gamma_{W}$ & 1.00 & 1.20 & 1.50 \\
$\gamma_{M}$ & 1.00 & 1.05 & 1.10 \\
\hline
\end{tabular}

\section{Conclusions}

In this work partial factors for façade scaffolds are derived, based on appropriate safety levels, considering the short life time of these structures and the possible reuse of the elements. This reuse of the elements has its influence on the costs and more specifically on the ratio of the failure cost to the initial cost, which was duly taken into account in the cost optimisation procedure. To derive appropriate partial factors, a probabilistic calculation method is set up, based on Latin Hypercube Sampling, structural calculations in a direct stiffness method based calculation program and FORM analyses. For these probabilistic calculations, a reference period of one year is adopted and three limit states are considered: yielding, the interaction between normal forces and bending moments and flexural buckling.

To be able to evaluate the structural reliability levels obtained through the probabilistic calculations, target reliability levels for façade scaffolds are necessary. This target reliability needs to take into account human safety requirements as well as economic considerations. For human safety, three target reliability levels are proposed based on literature: 2.3, 2.9 and 3.1. These values correspond to a reference period of 1 year, an admissible level of individual risk for temporary structures of $10^{-5}$ and different values of the conditional probability of casualty. An economic optimisation calculation is executed in accordance to (Van Coile, 2015, Van Coile et al., 2014). The minimum of the objective function varies depending on the assumed value of ratio $\xi$ of the failure cost to the initial cost, discount rate $\gamma$ and the scaffold class, among others. The most influencing parameter is the ratio $\xi$ of the failure cost to the initial cost. When varying 
this parameter, the reliability index corresponding to the absolute minimum of the objective function lies in the range of $\beta=2.50$ to $\beta=3.50$. Nevertheless, the objective function is quite constant around its minimum, thus slightly lower or higher values for $\beta$ could also lead to a feasible economic optimal solution On the basis of this preliminary investigation, the target value of $\beta$ should not be less than 2.3, which is the limit for human safety. For the determination of adjusted partial factors as executed in this contribution, three target reliabilities are considered: $\beta_{t}=2.5, \beta_{t}=3.0$ and $\beta_{t}=3.5$. These three values are close to the values imposed by the human safety requirements. Furthermore, these give a good representation of the range of the minima found in the economic optimisation when varying the ratio $\xi$ of the failure cost to the initial cost and considering the different scaffold classes. It might be pointed out that a lower scaffold class might be designed according to a lower target reliability, since scaffolds of higher classes might induce more severe consequences than those of a lower class.

Further, two methods are applied to determine appropriate partial factors corresponding to the assumed target reliabilities: an optimisation procedure based on least-square averaging and the adjusted partial factor method (APFM). However, it must be pointed out that both methods have another objective and approach the problem of determining the partial factors in a different way. With the optimisation procedure partial factors are derived not taking into account the values currently proposed in EN 12811-1. With this method, the optimal set of partial factors is calibrated in order to achieve an inherent reliability that lies as close as possible to the target reliability for different scaffold designs. The novel application of the previously developed APFM on the other hand starts from the partial factors currently found in EN 128111. In this method, the safety level is adapted relative to the reliability inherent to these partial factors, by multiplying the latter with adjustment factors. When the design is subsequently done according to the adjusted partial factors, the inherent reliability lies close to the target reliability assumed.

With both methods, partial factors are derived for the target reliability levels $\beta_{t}=2.5, \beta_{t}=$ 3.0 and $\beta_{t}=3.5$. For the APFM, graphs are provided where the adjustment factors can also be read for other target reliabilities. In general, the optimisation procedure leads to smaller values for the partial factors than the APFM, hence for the application considered the latter can be seen as a conservative approach to determine the partial factors for scaffold design. Considering the partial factors derived for $\beta_{t}=2.5$, both methods give considerably different results for the partial factor for the variable loads. However, for standardisation purposes, partial factors less than one are preferred to be replaced by $\gamma=1$. Accounting for this practical limitation, both methods conclude the same partial factors. Furthermore, for $\beta_{t}=3$, the factors resulting from both methods might lead to the same scaffold design, because partial factors that lie close to each other might result in the same ledger and transom lengths since these cannot be adapted continuously but only according to the practical available element lengths. Finally, also for $\beta_{t}=$ 3.5 , the partial factors obtained lie close to each other for both methods. These partial factors are approximately equal to the ones currently found in EN 12811-1, since the reliability index inherent to current design practice approaches 3.5. As a final conclusion, lower reliability levels than the one inherent to current design practice have been found to be appropriate for scaffold design. Accordingly, lower partial factors than those currently found in EN 12811-1 can be applied. This can induce more economical designs and reduce the costs of these temporary structures.

\section{References}

Abd Alghaffar, M. A., \& Dymiotis-Wellington, C. (2007). Time-variant reliability of retaining walls and calibration of partial factors. Structure and Infrastructure Engineering, 3(3), 187-198. doi:10.1080/15732470500440845 
Adeli, H., \& Sarma, K. C. (2006). Cost optimization of structures: fuzzy logic, genetic algorithms, and parallel computing: John Wiley \& Sons

André, J., Beale, R., \& Baptista, A. M. (2017). Risk analysis of bridge falsework cuplok systems. Structure and Infrastructure Engineering, 13(10), 1327-1349. doi:10.1080/15732479.2016.1265991

ASCE. (2002). Design loads on structures during construction. SEI/ASCE 37-02.

Baravalle, M., \& Köhler, J. (2019). A risk-based approach for calibration of design codes. Structural Safety, 78, 63-75. doi:10.1016/j.strusafe.2018.12.003

Cajot, L., Haller, M., Conan, Y., Sedlacek, G., Kraus, O., Rondla, J., ... Johansson, B. (2005). Probabilistic quantification of safety of a steel structure highlighting the potential of steel versus other materials. EUR(21695), 1-242.

Caspeele, R., Steenbergen, R., \& Sykora, M. (2016). Partial factor methods for existing concrete structures. (R. Caspeele, R. Steenbergen, \& M. Sykora, Eds.) (Vol. 80). Germany.

Caspeele, R., Steenbergen, R., \& Taerwe, L. (2012). An adjusted partial factor method for temporary structures compatible with the Eurocode framework. Civil Engineering and Environmental Systems, 30(2), 97-114. doi:10.1080/10286608.2012.733375

Caspeele, R., Sykora, M., Allaix, D. L., \& Steenbergen, R. (2013). The design value method and Adjusted Partial Factor Approach for existing structures. Structural Engineering International: Journal of the International Association for Bridge and Structural Engineering (IABSE), 23(4), 386-393. doi:10.2749/101686613X13627347100194

CEN. (2002). NBN EN 1990: Eurocode 0 - Basis of structural design. Brussels, Belgium.

CEN. (2004). NBN EN 12811-1: Temporary works equipment - Part 1: Scaffolds - Performance requirements and general design. Brussels, Belgium.

Eldukair, Z. A., \& Ayyub, B. M. (1991). Analysis of recent US structural and construction failures. Journal of performance of constructed facilities, 5(1), 57-73. doi:10.1061/(ASCE)0887-3828(1991)5:1(57)

Fiorillo, G., \& Ghosn, M. (2018): Risk-based importance factors for bridge networks under highway traffic loads, Structure and Infrastructure Engineering, doi:10.1080/15732479.2018.1496119

Fischer, K., Viljoen, C., Köhler, J., \& Faber, M. H. (2019). Optimal and acceptable reliabilities for structural design. Structural Safety, 76, 149-161. doi:10.1016/j.strusafe.2018.09.002

Gayton, N., Mohamed, A., Sorensen, J. D., Pendola, M., \& Lemaire, M. (2004). Calibration methods for reliability-based design codes. Structural Safety, 26(1), 91-121. doi:10.1016/S0167-4730(03)00024-9

Health and Safety Authority. (2005). Code of Practice for Access and Working Scaffolds. Ireland. Retrieved from:

http://www.hsa.ie/eng/Publications_and_Forms/Publications/Construction/Code_of_Practice_ for_Access_and_Working_Scaffolds.html

Holický, M. (2012). Optimisation of the target reliability for temporary structures. Civil Engineering and Environmental Systems, 30(2), 87-96. doi:10.1080/10286608.2012.733373

Holický, M. (2016). Specification of the Target Reliability Level. Paper presented at the 2016 Second International Symposium on Stochastic Models in Reliability Engineering, Life Science and Operations Management (SMRLO).

Holický, M., Marková, J., \& Sýkora, M. (2014). Target reliability levels in present standards. Transactions of the VŠB-Technical University of Ostrava, Civil Engineering Series. 14(2), 46-53.

ISO. (2015). ISO 2394:2015 General principles on reliability for structures. 4th ed. International Organization for Standardization 
JCSS. (2001). JCSS Probabilistic Model Code: Joint Committee of Structural Safety.

König, G., \& Hosser, D. (1982) The simplified level II method and its application on the derivation of safety elements for level I. CEB Bulletin 147

Layher. (2017). Layher technische brochure belastbaarheid allround- en systeemvrije onderdelen. Kontich, Belgium.

Layher (2018). Layher Allround Scaffolding - Instructions for assembly and use. Edition 04.2018. Ref. No. 8116.230. Gueglingen-Eibensbach, Germany

Rackwitz, R. (2000). Optimization - the basis of code-making and reliability verification. Structural safety, 22(1), 27-60. doi:0.1016/S0167-4730(99)00037-5

Scafom International b.v. (2010). Facade scaffold Framescaff: Technical Manual. www.scafom-rux.com

Sørensen, J. D., Kroon, I. B., \& Faber, M. H. (1994). Optimal reliability-based code calibration. Structural Safety, 15(3), 197-208. doi:10.1016/0167-4730(94)90040-X

Souder, C. (2014). Temporary Structure Design. John Wiley \& Sons.

Standards Australia/Standards New Zealand (2010). AS/NZS 1576.1:2010 Scaffolding General requirements, ISBN 9780733794353

Steenbergen, R., \& Vrouwenvelder, A. (2010). Safety philosophy for existing structures and partial factors for traffic loads on bridges. Heron, 55 (2), 2010. Retrieved from http://heronjournal.nl/

Tanner, P., Hingorani, R., \& Soriano, Juan. (2018). Safety requirements for the design of ancillary construction equipment. At the Sixth International Symposium on Life-Cycle Civil Engineering, IALCCE 2018, Life-Cycle Analysis and Assessment in Civil Engineering: Towards an Integrated Vision, At Ghent, Belgium

Toft, H. S., \& Sørensen, J. D. (2011). Reliability-based design of wind turbine blades. Structural Safety, 33(6), 333-342. doi:10.1016/j.strusafe.2011.05.003

Van Coile, R. (2015). Reliability-Based Decision Making for Concrete Elements Exposed to Fire (PhD Thesis). Ghent University, Belgium.

Van Coile, R., Caspeele, R., \& Taerwe, L. (2014). Lifetime Cost Optimization for the Structural Fire Resistance of Concrete Slabs. Fire Technology, 50(5), 1201-1227. doi:10.1007/s 10694-013-0350-9

VSB Vereniging van Steiger Hoogwerk en Betonbekistingbedrijven Bouwend Nederland. (2017). Richtlijn Steigers. Retrieved from http://www.richtlijnsteigers.com/

Zhang, H., Chandrangsu, T., \& Rasmussen, K. (2010). Probabilistic study of the strength of steel scaffold systems. Structural safety, 32(6), 393-401. doi:10.1016/j.strusafe.2010.02.005

Zhang, H., Rasmussen, K., \& Ellingwood, B. R. (2012). Reliability assessment of steel scaffold shoring structures for concrete formwork. Engineering Structures, 36, 81-89. doi:10.1016/j.engstruct.2011.11.027

Zou, Y., \& Ping Hong, H. (2011). Reliability assessment of FRP-confined concrete columns designed for buildings. Structure and Infrastructure Engineering: Maintenance, Management, Life-Cycle 31Design and Performance, 7:3, 243-258, doi:10.1080/15732470802416998 


\section{Appendixes}

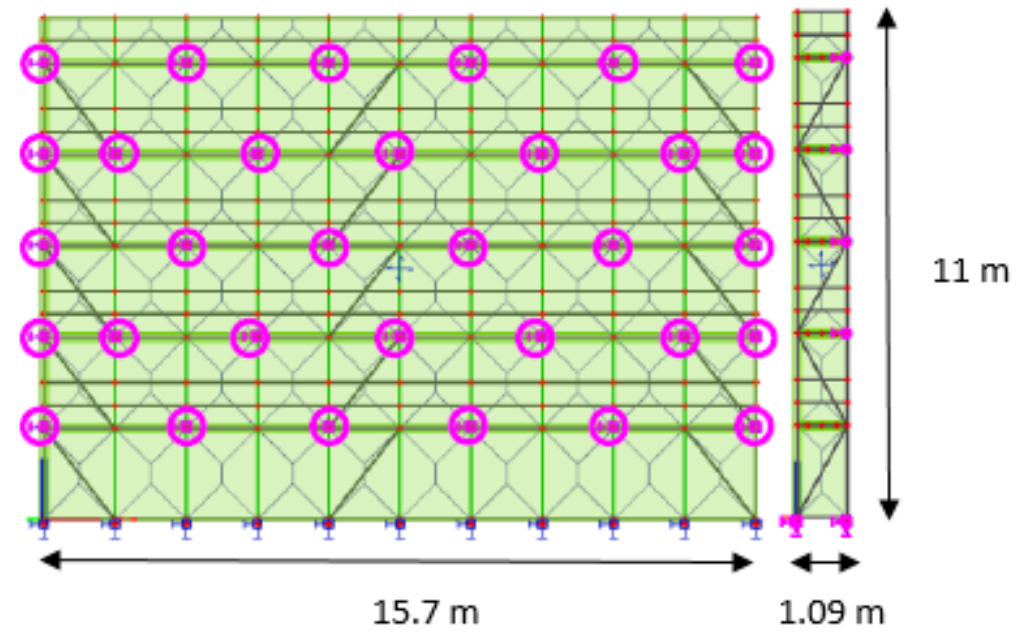

Figure A1. Design of a clad scaffold, anchorage points are encircled
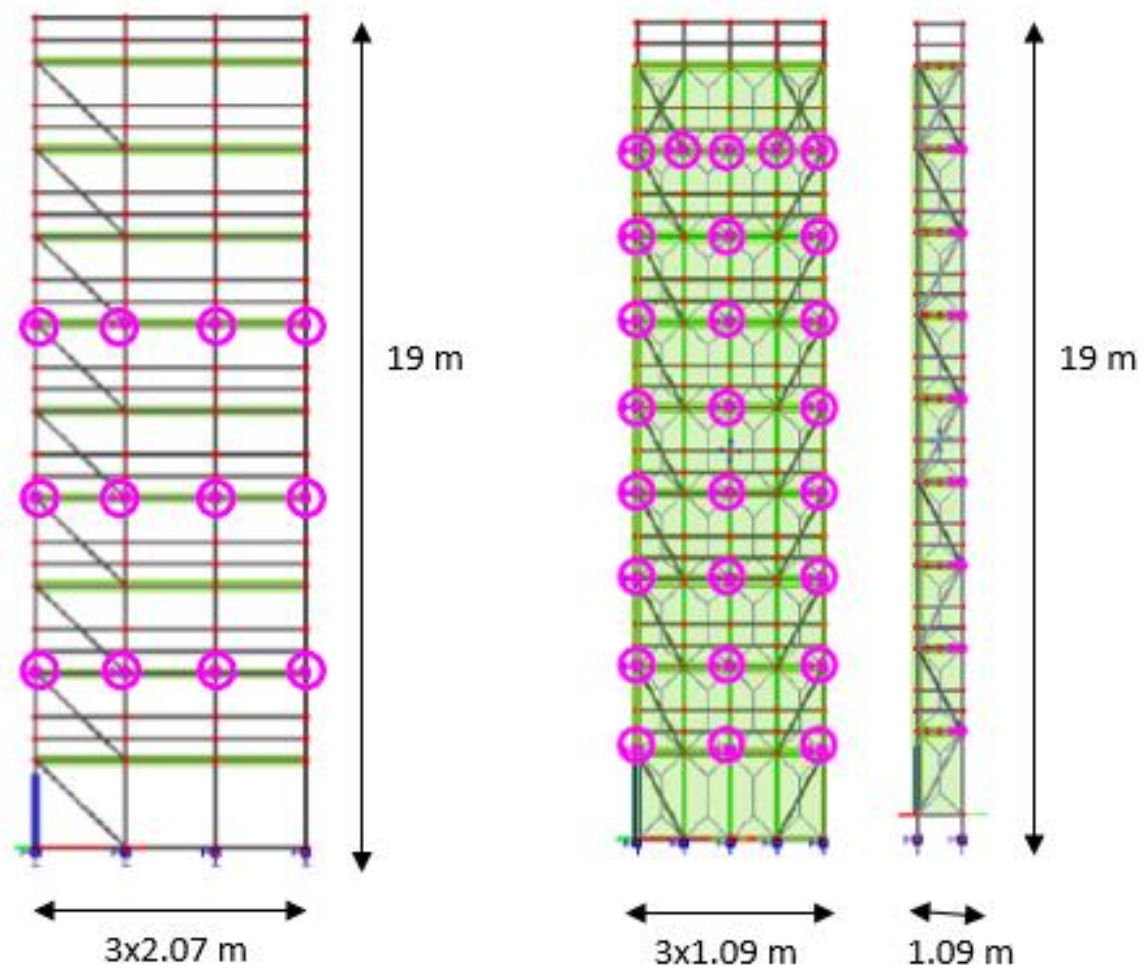

Figure A2. Design of scaffolds higher than the building they are anchored in, anchorage points are encircled 

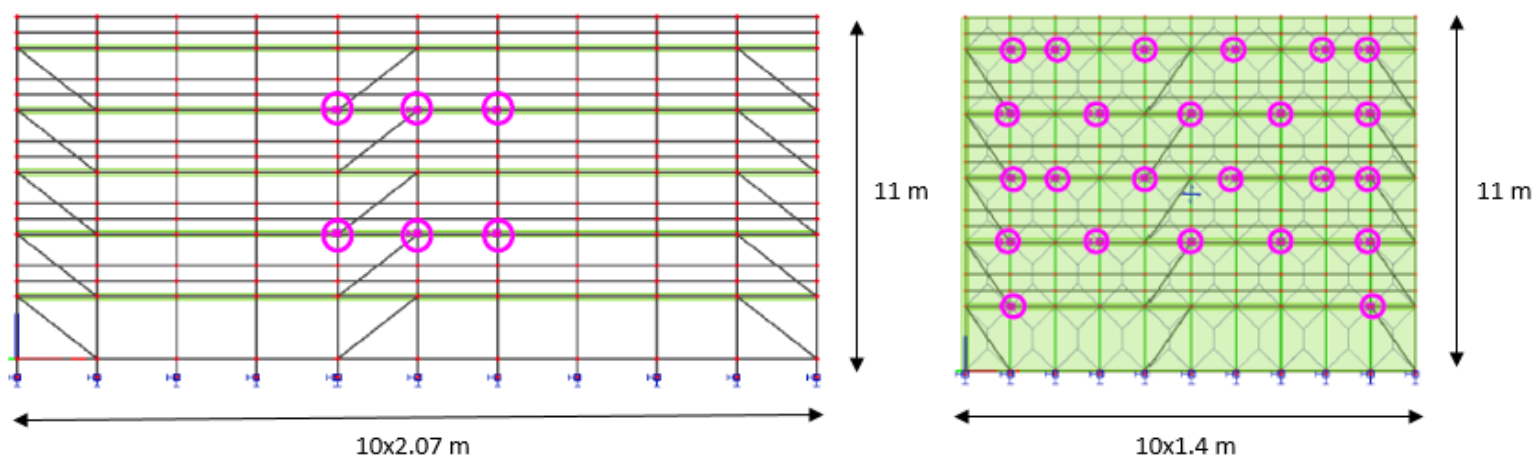

Figure A3. Design of scaffolds wider than the building they are anchored in, anchorage points are encircled

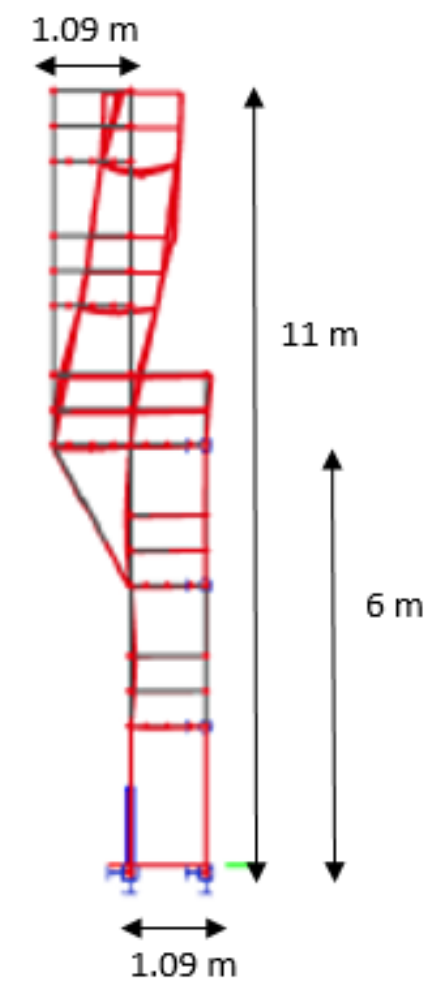

Figure A4. Design of a scaffold with a cantilevering part (length: 10 ledgers of $2.07 \mathrm{~m}$ ) 


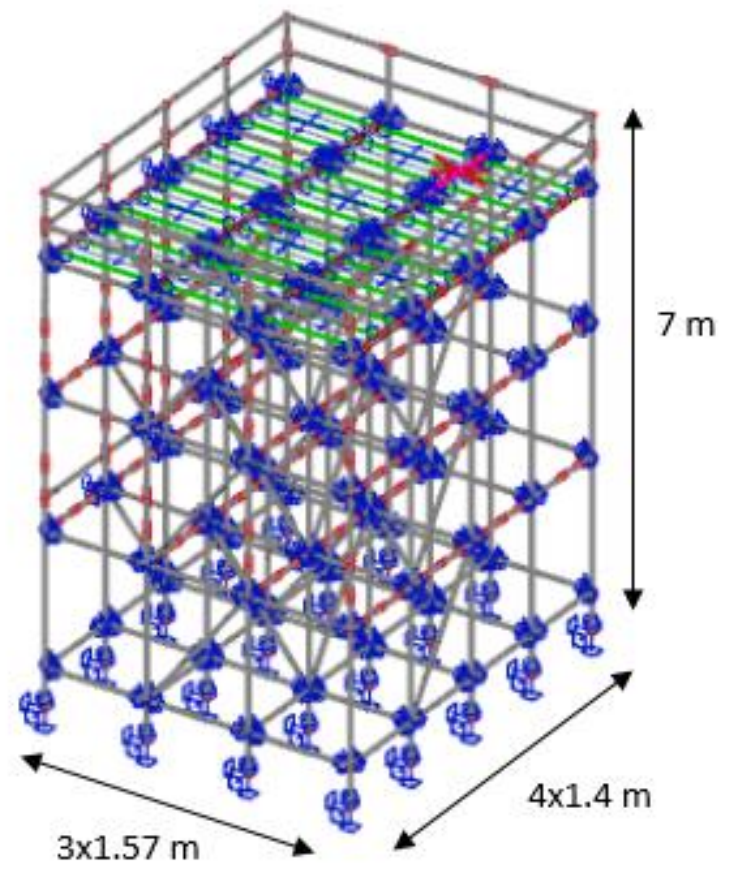

Figure A5. Design of an indoor space scaffold

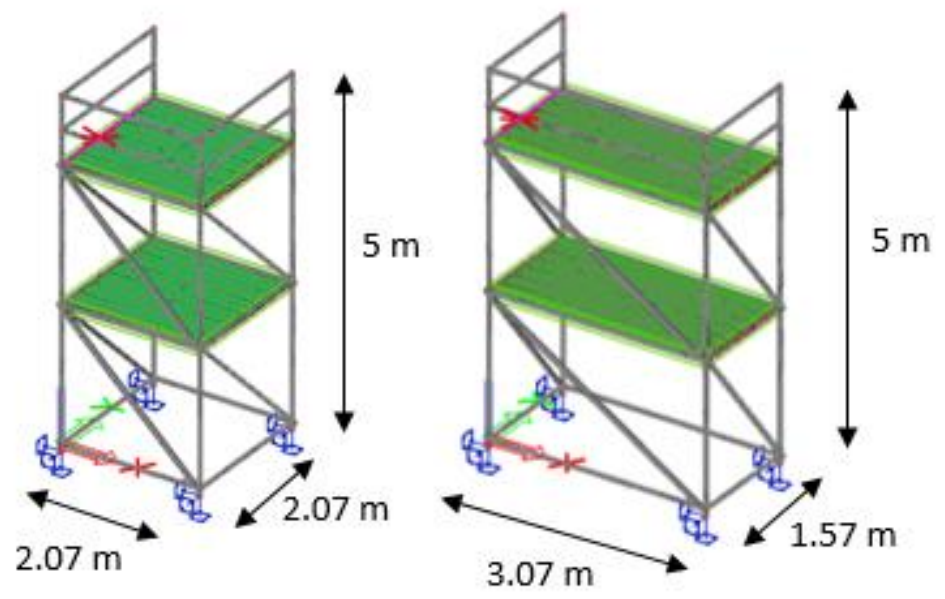

Figure A6. Design of self-standing scaffolds 